OPEN ACCESS

Edited by:

Roi Gazit,

Ben Gurion University of the

Negev, Israel

Reviewed by:

Nina Cabezas-Wallscheid,

Max Planck Institute for

Immunobiology and

Epigenetics, Germany

James Palis,

University of Rochester, United States

${ }^{*}$ Correspondence:

Katherine C. MacNamara

macnamk@amc.edu

Specialty section:

This article was submitted to

Cytokines and Soluble Mediators in

Immunity,

a section of the journal

Frontiers in Immunology

Received: 02 April 2020

Accepted: 08 June 2020

Published: 23 July 2020

Citation:

Seyfried AN, Maloney JM and MacNamara KC (2020) Macrophages Orchestrate Hematopoietic Programs and Regulate HSC Function During Inflammatory Stress.

Front. Immunol. 11:1499.

doi: 10.3389/fimmu.2020.01499

\section{Macrophages Orchestrate Hematopoietic Programs and Regulate HSC Function During Inflammatory Stress}

\author{
Allison N. Seyfried, Jackson M. Maloney and Katherine C. MacNamara* \\ Department of Immunology and Microbial Disease, Albany Medical College, Albany, NY, United States
}

The bone marrow contains distinct cell types that work in coordination to generate blood and immune cells, and it is the primary residence of hematopoietic stem cells (HSCs) and more committed multipotent progenitors (MPPs). Even at homeostasis the bone marrow is a dynamic environment where billions of cells are generated daily to replenish short-lived immune cells and produce the blood factors and cells essential for hemostasis and oxygenation. In response to injury or infection, the marrow rapidly adapts to produce specific cell types that are in high demand revealing key insight to the inflammatory nature of "demand-adapted" hematopoiesis. Here we focus on the role that resident and monocyte-derived macrophages play in driving these hematopoietic programs and how macrophages impact HSCs and downstream MPPs. Macrophages are exquisite sensors of inflammation and possess the capacity to adapt to the environment, both promoting and restraining inflammation. Thus, macrophages hold great potential for manipulating hematopoietic output and as potential therapeutic targets in a variety of disease states where macrophage dysfunction contributes to or is necessary for disease. We highlight essential features of bone marrow macrophages and discuss open questions regarding macrophage function, their role in orchestrating demand-adapted hematopoiesis, and mechanisms whereby they regulate HSC function.

Keywords: macrophage, hematopoiesis, HSC activation, niche, bone marrow, aplastic anemia, monocyte, inflammation

\section{INTRODUCTION}

At homeostasis the bone marrow is a dynamic tissue housing stem and progenitor cells that give rise to components of the blood and the immune system via a measured and continuous process called hematopoiesis $(1,2)$. The bone marrow is a unique tissue; it is the origin for our immune cells, a site where billions of cells die and are removed, the production-site for red blood cells and platelets, and it is also the home for memory lymphocytes and plasma cells. Cell proliferation and differentiation, cell death and clearance, and cell migration create a dynamic microenvironment in the bone marrow. A variety of hematopoietic and non-hematopoietic cells interact in the bone marrow creating cellular niches that support hematopoietic stem cell (HSC) and progenitor cell (HSPC) survival and differentiation. HSCs and HSPCs reside at the apex of the hematopoietic hierarchy, giving rise to all cells of the blood and immune system. In healthy conditions, blood production relies on the contribution of HSPCs, whereas long-term HSCs remain quiescent, 
dividing rarely (3), and contributing little to steady-state blood production (4). Distinct populations of HSPCs can be characterized by expression of specific receptors and proteins, corresponding to lineage-biased blood production as observed in transplantation assays $(5,6)$. These findings support the notion that specific populations of HSCs/HSPCs are primed for producing certain cell types, though inherent plasticity exists in these populations. In response to trauma or injury, phenotypic changes and altered functional outputs demonstrate the flexibility of the hematopoietic compartment and its ability to be tailored to meet specific demands.

Inflammation, via production of inflammatory factors including cytokines and interferons, has been demonstrated to impact the differentiation and function of HSCs and HSPCs, highlighting the incredibly adaptive nature of the hematopoietic system. In direct response to pattern recognition receptor (PRR) stimulation $(7,8)$, cytokine signaling (9), and interferon stimulation (10-14), HSC and HSPC proliferative capacity, survival, and lineage commitment can change rapidly. An additional level of complexity exists in vivo as HSCs and HSPCs reside in particular regions or niches that provide signals to direct proliferation, differentiation, and/or quiescence. Here we focus on the unique role of macrophages in directing HSC and HSPC function and regulating hematopoietic responses during organismal stress, such as infection, autoimmunity, and aging. The ability to modulate HSC function by targeting the niche is important for clinical procedures, such as HSC mobilization, and holds potential for treating blood disorders including hematopoietic malignancies and marrow failure.

\section{MACROPHAGES: MANAGERS OF TISSUE HOMEOSTASIS}

Macrophages are a heterogenous population of terminally differentiated cells that can be found in all tissues, including the bone marrow, where they perform essential homeostatic functions that include tissue remodeling, clearance of dead cells, and production of angiogenic factors (15). Macrophages are members of the mononuclear phagocyte system, which also consists of monocytes and dendritic cells (16). Named for their remarkable phagocytic capacity described over a century ago by Metchnikoff (17), macrophages express a variety of receptors that enable efficient phagocytosis, including complement receptors, Fc receptors (for immunoglobulins), and scavenger receptors [reviewed in (18)]. In addition to their ability to "eat," macrophages sense endogenous and microbeassociated danger and damage signals via pattern recognition receptors (PRRs) such as Toll like receptors (TLRs), lectin sensing receptors, mannose binding receptors, and cytoplasmic NODlike receptors. With the profound array of receptors to both ingest and sense their surroundings, they are positioned to act as highly sensitive detectors of environmental stress. In response to the substances ingested and the danger- and pathogenassociated molecular patterns (DAMPs and PAMPs, respectively) encountered, macrophages produce a variety of soluble and membrane-associated factors that can act in the immediate vicinity to modulate cell function and biological activities.

\section{Developmental Origins of Tissue Macrophages}

Tissue macrophages are diverse in their ontogeny, arising from the embryonic yolk sac, fetal liver, or from post-natal bone marrow. Primitive macrophage progenitors arise from the yolk sac to seed the developing tissues, including brain and fetal liver, giving rise to microglia in the brain and premacrophages in the fetal liver $(19,20)$. Notably, yolk sac-derived progenitors have macrophage, but not monocyte, potential and do not require a monocyte intermediate in becoming microglia (20). Subsequently, yolk sac-derived erythro-myeloid progenitors (EMPs), which contain macrophage, as well as granulocyte/monocyte and mast cell potential, arrive in fetal liver, where they undergo differentiation into pre-macrophages and monocytes (19-21). Fetal-liver pre-macrophages differentiate into fetal monocytes, emigrate from the liver, and, upon entering tissues, rapidly initiate transcriptional programs due to microenvironmental cues which drive maturation and specification into tissue-resident macrophage populations. In splenic red pulp, heme-sensing drives proteasomal degradation of Bach1, thus de-repressing Spic expression, the master transcriptional regulator for red pulp macrophage specification (22). Liver-resident macrophages, Kupffer cells, require liver $\mathrm{X}$ receptor (LXR)- $\alpha$ activation and Id3 transcription (23, 24). Whereas, most tissue macrophages require M-CSF for survival, GM-CSF secretion by lung epithelium drives alveolar macrophage specification via PPAR- $\gamma(25,26)$. Underscoring the heterogeneity of tissue macrophages, the kidney contains at least three macrophage subsets with distinct ontogenies and inflammatory profiles (27). The conditions necessary for specification into bone marrow-resident macrophages are currently unclear. Deletion of Spic or Irf8 partially block bone marrow macrophage specification $(22,28)$, but a universal transcriptional program for the bone marrow remains elusive, perhaps due to the heterogeneity of macrophages in this tissue.

Although there are few to no immunophenotypic markers useful for distinguishing embryonic- from HSC- or monocytederived macrophages, lineage-tracing, and transgenic models have revealed valuable insights about macrophage ontogeny. In a seminal study, Hashimoto et al. (29) demonstrated that microglia, lung, red pulp, peritoneal, and bone marrow macrophage populations arose independently of adult HSCs and monocytes in a self-renewing manner $(29,30)$. More recently, Ms4a3, a monocyte lineage-specific gene expressed in granulocytemonocyte progenitors (GMPs), was used to track post-natal seeding of tissues with monocyte-derived macrophages and identified tissue resident macrophage populations that were not replenished by monocytes (including Langerhans cells, Kupffer cells, and microglia) at steady state (30). The authors further demonstrate that bone marrow macrophages arise from $M s 4 a 3^{-}$ monocyte-dendritic cell progenitors (MDPs), which did not share ontogeny with monocytes derived from $\mathrm{Ms}_{4} a 3^{+}$GMPs, indicating that steady state tissue-resident macrophages and 
monocytes arise from separate lineages. These studies further demonstrated three modes of macrophage replacement in postnatal mice as they reach adulthood: fast replacement (blood, dermis, and gut), slow replacement (spleen, peritoneum, and kidney), or no replacement (microglia, epidermal Langerhans cells, and Kupffer cells) as predicted in previous studies (31, 32). The significance of the origin of distinct macrophage populations is a topic of intense interest as macrophages derived from embryonic hematopoiesis may be functionally distinct from those derived from adult hematopoiesis, and how distinct macrophage populations, monocyte-derived or tissue resident, contribute to health, and disease is unclear. In order to study the contribution of embryonic macrophages, macrophage egress was blocked from fetal liver by deleting the gene encoding plasmalemma vesicle-associated protein (PLVAP). PLVAP is the protein responsible for forming fenestrae in liver sinusoidal endothelium which allows pre-macrophages to migrate from the fetal liver to seed other tissues $(33,34)$. Adult mice lacking PLVAP display a striking absence of fetal liver-derived macrophage populations in the spleen, peritoneum, liver and lung, while tissue macrophages derived from adult hematopoiesis and yolk sac-derived microglia were unaffected. This study demonstrated that macrophage ontogeny can carry functional ramifications as pathologic levels of iron storage were observed in 5 week-old Plvap ${ }^{-/-}$livers and spleens, despite unimpaired entry of HSC-derived monocytes. Thus, embryonic liver-derived tissue-resident macrophages may have a unique capacity for iron trafficking in adult tissues, and this mouse model may be particularly useful in examining bone marrow macrophage ontogeny.

When steady state conditions are interrupted, as seen in response to inflammation or injury, tissue resident macrophages of embryonic origin may be replenished by monocytes in a competitive manner. Partial depletion of embryonically derived Kupffer cells in the adult liver enabled monocytes to replenish the empty niche over several days and differentiate into cells largely resembling their embryonically-derived counterparts, differing only subtly in their expression of genes related to efferocytosis, pathogen recognition, and heme scavenging (35). The remaining embryonically-derived Kupffer cells became more proliferative and increased in number during this period (35), similar to observations in the heart (36), lung (37), and brain (38) following infection or injury. Thus, adult monocytes have the capacity to infiltrate most tissues and replace embryonically-derived macrophages. Questions remain as to whether replacement of bone marrow resident macrophages requires monocyte infiltration from circulation, or whether they mature in situ without ever leaving the bone marrow.

\section{Macrophage Functional Plasticity}

Depending on the signals they receive, macrophages can adopt unique functional characteristics ranging from classical or proinflammatory activation (referred to as M1 polarization), to alternatively activated or pro-resolving/M2 phenotypes. The concept of "polarization" was proposed to describe in vitro differentiated macrophages and classify distinct functional and phenotypic programs (39), though these programs are vastly more complicated and nuanced in vivo $(40,41)$. Tissue-resident macrophages typically exhibit expression of Arginase1 (42) consistent with their ability to proliferate in response to Th2 cytokines, such as IL-4 (43), and secrete IL-10 and TGF $\beta$ driving their ability to dampen inflammation and drive wound healing (40). Classically activated macrophages, induced by Th1 cytokines such as IFN $\gamma$ and TLR4 stimulation by bacterial lipopolysaccharide (LPS), secrete IFN $\gamma$ and tumor necrosis factor (TNF) and express inducible nitric oxide synthase (Nos2) thus enhancing the respiratory burst, and facilitating the killing of intracellular pathogens. The diversity of macrophage phenotypes observed in vivo blurs the current paradigm of polarization and highlights the context-dependence of macrophage function.

Clearance of apoptotic cells by macrophages (i.e., efferocytosis) is a fundamental process that accounts for the efficient and continuous removal of billions of dead, damaged, or unwanted cells each day. Efferocytosis is mediated by the recognition of apoptotic cells via exposure of phosphatidylserine (PtdSer) on the plasma membrane and through the release of factors that act as "find me" signals (44). Apoptotic cells can be sensed directly by phagocytes, via PtdSer receptors including the $\mathrm{T}$ cell immunoglobulin and mucin (TIM) family of receptors and others (45), or are recognized by phagocytes indirectly via receptors that bind protein S or Gas6, plasma proteins with affinity for PtdSer that act as bridging molecules [reviewed in (46)]. Stimulation of Tyro3, Axl, and MerTK (TAM) receptor signaling activates expression of suppressor of cytokine signaling (SOCS) proteins, inhibitors of signaling downstream of TLRs and interferon receptors $(47,48)$. In addition, MerTK signaling promotes the synthesis and release of pro-resolving lipid mediators by altering metabolic pathways $(49,50)$, and mice lacking MerTK and Axl have greater basal levels of proinflammatory factors, including IFN $\gamma$ and TNF (51). MerTK signaling also promotes macrophage survival, proliferation, and migration (52-54). Expression of TAM receptors is under control of cytokine receptors, thus appropriate temporal regulation of efferocytosis and pro-resolving macrophage phenotypes should occur sequentially upon inflammatory signaling (47).

Macrophages are poised to participate in the rapid response to damage and danger as they are equipped with machinery to both activate inflammation and promote wound healing and tissue regeneration. Whereas, inflammatory responses are critical for host defense and immunity, the capacity to restore homeostasis is essential for maintaining tissue integrity and functionality. Therefore, macrophages are essential "bookends" to the cyclic and episodic inflammatory events encountered throughout life, and as such, their function may reveal insight to understanding how inflammatory stress impacts HSC function.

\section{MACROPHAGE-DEPENDENT REGULATION OF THE HEMATOPOIETIC SYSTEM}

\section{Macrophages Instruct HSC Emergence}

Macrophages, along with primitive erythrocytes and megakaryocyte progenitors are among the earliest differentiated 
cell types to emerge in the yolk sac, prior to the existence of HSCs $(19,55)$. During the earliest stages of life macrophages are essential in shaping the developing embryo, primarily through their ability to remove and clear dead cells; without this essential function, profound defects occur in the developing brain and lung (56). Development of the blood system occurs in several stages, with the final wave being when HSCs emerge (57-59). In the aorta-mesonephros-gonad (AGM) region, a transient window of endothelial-to-hematopoietic lineage specification occurs allowing emergence of HSCs (58), and specific inflammatory signals, including IFN $\gamma$, are required for this process (60). Using Csf1r reporter mice EGFP-positive macrophages appeared in the mesenchymal tissue of the aorta and in the lumen prior to HSC emergence (61), similar to findings in human tissue (62). These observations suggest that primitive macrophages migrate through the vasculature, localize to the site of HSC emergence, and are instructed to accumulate prior to emergence of HSCs. Macrophages were positioned such that they interacted with $\mathrm{c}-\mathrm{Kit}^{+}$progenitors entering the lumen, supporting the conclusion that they promote HSC emergence from the endothelium (63). Specific chemokines mediated $\mathrm{CX}_{3} \mathrm{CR} 1$-dependent recruitment of a unique macrophage population to the AGM that exhibited characteristics of both resident macrophages and inflammatory macrophages (63). The inflammatory signaling pathways required during development and HSC emergence are reactivated during stress and injury and suggest macrophages possess powerful regenerative capacity that may impact HSC function in adults.

\section{Bone Marrow Macrophages and HSC Niches}

The bone marrow contains defined anatomical niches that maintain HSCs via a complex network of secreted factors, cellmatrix contacts, and cell-cell interactions (64). These niches maintain HSCs through extracellular matrix and stem cell factor (SCF) secreted by osteoblasts, mesenchymal stromal cells (MSCs), and arteriolar endothelial cells (65-67). Other factors, such as CXCL12 promote HSC retention and quiescence (68). Macrophages are integrated throughout the bone marrow and exist in the various HSC niches that have been described. Macrophage crosstalk with Nestin ${ }^{+}$niche cells results in Cxcl12 transcription and, following macrophage depletion, expression of Cxcl12 (as well as other HSC maintenance and retention factors Angpt1, Kitl, and Vcam1), is lost, and HSCs egress from the marrow (69). How macrophages modulate HSC niches is not yet fully understood, but as their function can impact the cellcell interactions and the microenvironment, we suggest they play underappreciated roles in modulating HSC function. A variety of different macrophage populations have been described by both phenotype and function [reviewed in (70)] and their location and function in the bone marrow encompass a spectrum of biological roles with implications on HSC function (Figure 1).

\section{Macrophages in Endosteal Niches}

Macrophages are key regulators of bone homeostasis, a dynamic process involving many cell types and continuous remodeling [reviewed in (64)]. The main bone forming cells, osteoblasts, derive from mesenchymal progenitors aided by macrophage signals (Figure 1A) and were among the first cell types demonstrated to regulate the size of the HSC pool (65). Osteoclasts are multinucleated bone resorbing cells that arise from the common myeloid progenitor lineage in response to M-CSF and RANKL signaling, and have recently been shown to be long-lived cells fusing with circulating monocytes [(71); Figure 1B]. Osteoclast-committed progenitor cells respond to the cytokine osteoprotegerin, which induces commitment to the osteoclast lineage (72). Whereas M2 polarizing signals promoted osteoblast differentiation and bone mineralization in vitro, M1-polarized macrophages had the opposite effect, thus demonstrating how macrophage-mediated inflammation impacts bone formation (73).

Distinct from osteoclasts are a subset of macrophages termed "osteomacs" that reside along the bone lining in close association with osteoblasts and megakaryocytes and were found to play key regulatory roles in modulating osteoblast function [(74); Figure 1C]. The interaction between macrophages and osteoblasts was necessary for low-level activation of nuclear factor $\kappa \mathrm{B}(\mathrm{NF}-\kappa \mathrm{B})$ in osteoblasts and their ability to maintain HSCs through appropriate chemokine signaling (75). Osteomacs were found to be supported by the presence of megakaryocytes and their interactions together synergized with osteoblasts to regulate HSC repopulating potential as tested in transplantation assays (76). The supportive role that macrophages play in regulating a variety of biological processes in bone turnover and MSC function suggests that their activation state is an important regulator of HSC function.

\section{Erythroblastic Island Macrophages}

Macrophages play a fundamental role in the development and life of red blood cells, supporting both the birth of erythrocytes and controlling their removal upon completion of their $\sim 90$-day lifespan $(77,78)$. Erythroblastic island (EBI) macrophages are a unique, EpoR-expressing population in the bone marrow [(79); Figure 1D]. These macrophages "nurse" committed erythroid progenitors (EPs) through the process of becoming enucleate reticulocytes via the provision of growth factors, potentially supplying iron that EPs incorporate into heme, and finally by engulfing and destroying the pyrenocyte, the product of asymmetric erythroblast cell division containing the nucleus, plasma membrane, and a small amount of hemoglobin-rich cytoplasm $(80,81)$. Among the many signals required for efficient erythropoiesis is EpoR (erythropoietin receptor) signaling, essential for the terminal maturation of erythroid-lineage cells in adult erythropoiesis (82). In addition to its expression on erythroid lineage cells EpoR is expressed by a variety of macrophage populations throughout the body, where its signals induce pleiotropic cytoprotective (83) and immunomodulatory effects (84). EpoR signaling in peritoneal macrophages enhanced PPAR $\gamma$-mediated expression of efferocytosis machinery, increased TGF $\beta$ production, reduced production of IL-6, TNF, IFN $\alpha$, and IFN $\beta$, but did not significantly affect levels of IL-10, IL-12, or $\operatorname{IFN} \gamma(85,86)$, reflecting specificity in macrophage signaling output. Moreover, imbalances in these cytokines were detected in the serum of adult 


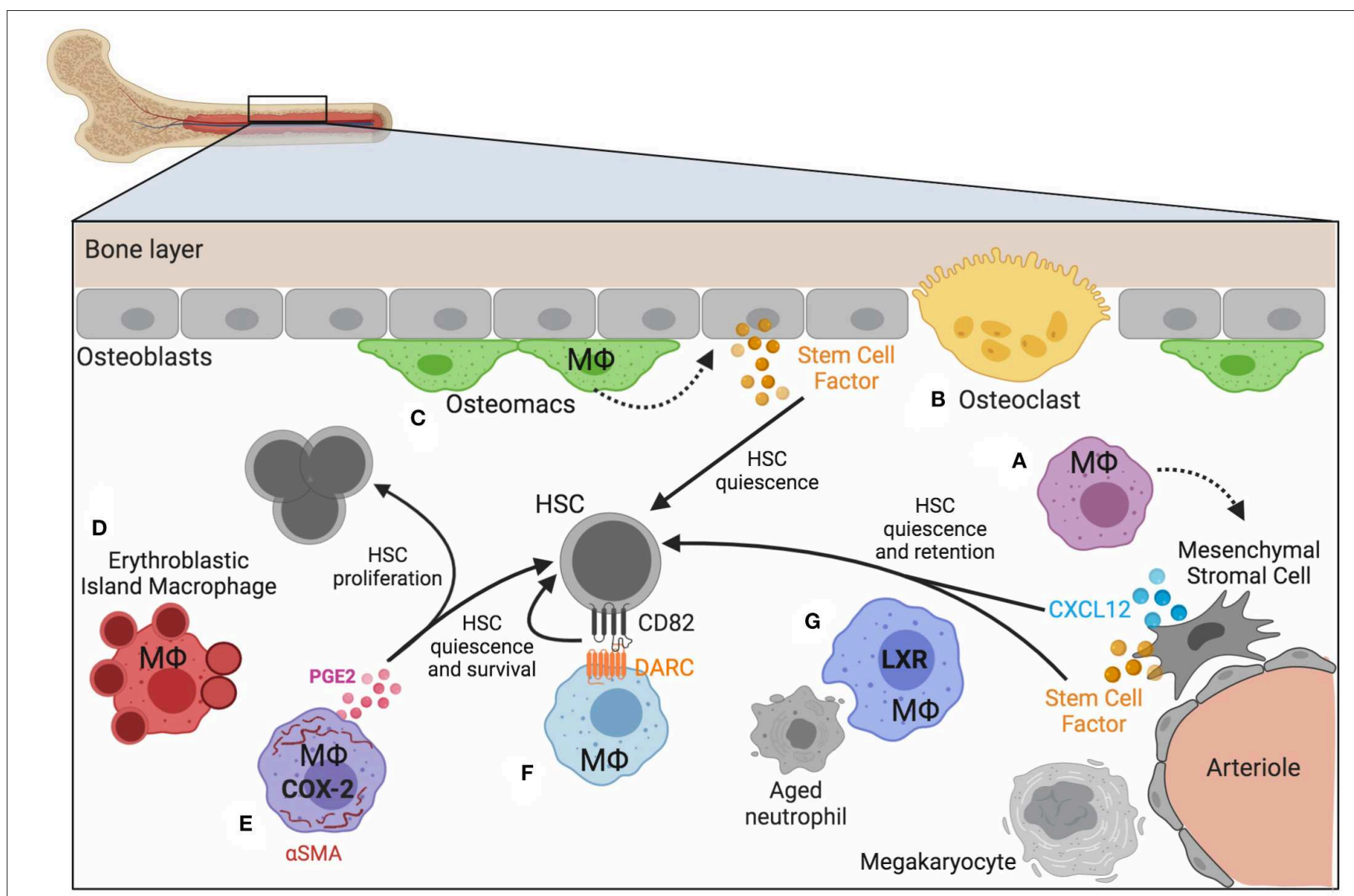

FIGURE 1 | Macrophage heterogeneity in bone marrow and HSC niches. Homeostasis of blood production depends on bone marrow niches that regulate the location and function of HSCs and progenitors. Macrophages play both direct and indirect roles in maintaining HSC quiescence and maintenance. (A) Mesenchymal stromal cells respond to signals provided by nearby macrophages. (B) Specialized, multinucleated macrophages (osteoclasts, yellow) and (C) a distinct subset of macrophages have been identified near the bone lining (osteomacs; green). (D) Macrophages associate with developing erythroid progenitors (erythroblastic island macrophages; red), and (E-G) macrophages that express aSMA (purple), DARC (light blue), and LXR (dark blue) have been demonstrated to impact hematopoiesis and HSC function. Figure generated using BioRender.com.

mice in which macrophages lacked EpoR, which coincided with the development of a systemic, lupus-like disease (87).

EBI macrophages have been described as $\mathrm{EpoR}^{+}$but if, and how, EpoR signaling in EBI macrophage functions relative to blood production is unknown. Relative to other $\mathrm{BM}$ macrophages, $\mathrm{EpoR}^{+} \mathrm{EBI}$ macrophages were found to express elevated MerTK and Axl (but not Tyro3) at steady state (79). Because EBI macrophages constantly efferocytose pyrenocytes, disrupted TAM receptor signaling in these cells during inflammatory stress may contribute to inflammatory anemias. A role for direct Epo signaling in HSPCs is not likely as mice expressing a constitutively active EpoR mutant, R129C, exhibited an expanded erythroid- and granulocyte/monocytelineage compartment, whereas other hematopoietic lineages were normal (88-90). Committed erythroid progenitors were recently found to localize near sinusoidal endothelium, occupying niches with HSCs and requiring signals from Leptin receptor ${ }^{+}$ MSCs (91). As macrophages likely share these niches with progenitors, their function and activation may contribute to both erythroid progenitor and HSC location. Consistent with this notion is the observation that macrophage depletion results in HSC mobilization (discussed in more detail below) as well as a profound loss in medullary erythropoiesis that coincides with extramedullary erythropoiesis. As macrophage depletion diminishes Cxcl12 expression, it is possible that immediate release of HSCs into circulation occurs very rapidly from these erythroid and HSC niches.

\section{Direct Interactions With HSCs}

A rare subset of macrophages expressing the fibroblastic marker, alpha-smooth muscle actin ( $\alpha \mathrm{SMA})$, was shown to directly interact with primitive HSPCs in bone marrow [(92); Figure 1E]. Using an $\alpha \mathrm{SMA}$ reporter mouse to identify vasculature niche pericytes, these macrophages were found to be migratory and more abundant upon stimulation with LPS. Furthermore, they expressed high levels of cyclooxygenase-2 (COX-2), which was important for preserving primitive HSPCs under inflammatory stress conditions, via PGE-2-dependent HSPC survival (93). One day post-radiation COX-2 expression and PGE-2 production increased among $\alpha \mathrm{SMA}^{+}$macrophages, and these changes 
were found to preserve HSC quiescence. The timing of this response was critical, however, as addition of PGE-2 at later stages was found not to be protective. PGE-2 can impart both pro-inflammatory and anti-inflammatory signals, depending on engagement with specific receptors, and also signals in many different cell types in vivo. Therefore, the impact of PGE-2 on HSCs in vivo is likely highly dependent on both the timing and cellular context.

Macrophage-dependent regulation of HSC quiescence may also occur via the tetraspanin CD82, expressed on HSCs, and its interaction with the pseudo-chemokine receptor Duffyantigen associated receptor (DARC), expressed on a subset of macrophages in the bone marrow [(94); Figure 1F]. Tetraspanins have previously been shown to promote quiescence of HSCs (95) and CD82 was found to regulate HSC adhesion via altering integrin stability and density on the plasma membrane and ultimately enforcing dormancy that was dependent on TGF $\beta$. Due to the lack of a G-protein coupling motif, DARC acts as a chemokine "sink" because it can bind chemokines but does not transmit signals (96), and as such may be primarily expressed by macrophages that are programmed to be anti-inflammatory, thus creating an anti-inflammatory microenvironment. DARC is expressed by endothelium and also found on red blood cells, and how DARC may regulate the local microenvironment in the bone marrow is a topic that needs further investigation.

In line with evidence that macrophages regulate HSC function in vivo, macrophage polarization was shown to impact HSC selfrenewal in vitro (97). Using an ex vivo HSC expansion model, macrophages cultured with IFN $\gamma$ or IL- 4 were subsequently cocultured with LSK cells to analyze cobblestone area-forming cells (CAFCs) and subjected to transplantation to evaluate function. Macrophages cultured with IFN $\gamma$ increased expansion of LSK cells, but significantly reduced the number of CAFCs. In contrast, macrophages cultured with IL-4 reduced expansion of LSK cells but increased the number of CAFCs. Using Nos2 and Arg1 knockout mice the effects on LSK expansion and CAFC formation were reversed suggesting that increased HSC selfrenewal is partly due to increased Arg1 expression. HSC selfrenewal was suggested to be due to an increase in spermidine, a result of arginase metabolism, and enhanced expression of Ezh2 and Gif1, key genes related to self-renewal. Thus, the metabolic programing of macrophages can instruct HSC proliferation and determine self-renewing vs. differentiating cell division choices, and the precise molecular programming driving these fate choices will be important to decipher. As macrophages are integrated throughout the bone marrow niche and can interact directly with HSCs, defining the proximity and function of distinct macrophage populations may yield in vivo approaches to target HSC function.

\section{HSCS ON THE MOVE: MACROPHAGES REGULATE HSC LOCATION}

\section{HSC Mobilization}

In healthy conditions HSCs and HSPCs are enriched in the bone marrow, though they are released at low numbers into circulation and can enter extramedullary tissues (98). This homeostatic mobilization is dependent upon circadian rhythmdependent responses (99) and linked to the mobilization and clearance of neutrophils in the bone marrow $(100,101)$. The relatively short lifespan of a typical neutrophil requires not only rapid production but efficient removal of expired, or "aged," neutrophils. Tracking the kinetics of neutrophils in the blood revealed dynamic modulation of newly released neutrophils and loss of phenotypic aged neutrophils that corresponded to circadian fluctuations (101). Clearance of neutrophils in the bone marrow induced changes in the local niche microenvironment, including reduced expression of CXCL12, and concurrent increase in blood progenitors. Macrophages were necessary for neutrophil clearance and activated LXR-dependent programs that promote apoptotic cell clearance (Figure 1G). This seminal study demonstrated a direct link between macrophage function and the homeostatic, daily release of hematopoietic progenitors. Lifestyle stress that interferes with normal circadian-dependent processes is, therefore, likely to impact HSC and HSPC mobilization, the consequences of which are not yet fully understood. It is intriguing to speculate how perturbation of macrophage phagocytic capacity, such as that observed during inflammation or resolution, impacts HSC function via regulation of the bone marrow niche.

Mobilization of HSCs and HSPCs can be rapidly induced by inflammatory signaling, a process that synchronizes with granulocyte production and their release into circulation (102104). HSC mobilization and granulopoiesis can be induced by the growth factor granulocyte colony stimulating factor (G-CSF) that results in profound decrease in Cxcl12 (105-107). G-CSF receptor signaling is not required in hematopoietic progenitors themselves (108), however, and G-CSF-driven HSC mobilization was found to require macrophages (109). G-CSF results in specific and profound decrease in bone marrow macrophages, whereas other tissues such as spleen do not experience this decrease $(110,111)$. Therefore, local loss of macrophages in the bone marrow promotes HSC mobilization, consistent with observations that clodronate-loaded liposome (Clod-lip)mediated macrophage depletion induces HSC mobilization, and significantly enhanced G-CSF driven HSC mobilization (69). The increase in circulating HSCs in these conditions has been attributed to a reduction in the chemokine CXCL12 and other HSC retention signals $(69,112)$. The loss of these retention factors, some of which also enforce quiescence, may contribute to the transient expansion of the HSC/HSPC pool as Clod-lipmediated depletion of macrophages was also found to correlate with increased HSCs/HSPCs in the bone marrow (113). Analysis of HSC proliferation and quiescence upon Clod-lip treatment revealed a transient increase in proliferation among phenotypic HSCs, followed by an increased proportion of quiescent HSCs, suggestive of self-renewing proliferation (113).

\section{Returning Home: Engraftment}

In addition to regulating HSC mobilization, macrophages were found to be critical for bone marrow engraftment of HSCs following transplantation (114). A proportion of macrophages in bone marrow exhibited radio-resistance and relative persistence 
for more than 1 month post-radiation. These radio-resistant macrophages were necessary for efficient HSC engraftment and reconstitution of the hematopoietic system after lethal irradiation, as diphtheria toxin receptor (DTR)-dependent depletion of CD169-expressing macrophages reduced HSC engraftment. These studies highlight that bone marrow-resident macrophages can persist after lethal radiation. This finding impacts conclusions from studies where radio-resistant cells have been implicated in specific responses. It is not surprising that macrophages can persist subsequent to radiation as tissueresident macrophages may be slowly cycling or not proliferating, and also have the capacity to self-renew in response to $\mathrm{M}$ CSF. Expansion of host macrophages after radiation can be increased by exogenous M-CSF and reduces graft vs. host disease supporting a protective role for resident macrophages in reducing inflammation in the context of transplantation (115).

In a separate study, macrophage depletion was found to promote HSC recruitment and retention in the bone marrow leading to stable hematopoietic chimerism (116). While seemingly in contrast to the observation by Kaur et al. that macrophage depletion reduces HSC engraftment (114), the exposure to macrophage depletion in combination with lethal, ionizing radiation, likely induced a distinct pro-inflammatory microenvironment impairing engraftment. In contrast, Clodlip-dependent macrophage depletion alone may not elicit the same extent of inflammation. These differences raise important caveats pertaining to interpretations of studies using macrophage depletion methods, as these techniques modulate inflammation and impact other cells in vivo. Macrophage depletion using Clodlip has been studied by many laboratories and the mechanism of depletion involves apoptotic cell death of the liposome-engulfing cell upon intracellular release of the bisphosphonate (117). It is important to consider that the process of macrophage depletion via apoptosis will simultaneously generate many apoptotic cells and remove professional phagocytes that typically clear apoptotic cells. Increased apoptotic cells will lead to an accumulation of factors that act as "find me" signals priming surrounding cells for apoptotic cell clearance. It is also important to note that depletion models are not effective at ablating cell populations entirely and the homeostatic mechanisms maintaining tissue macrophages are immediately activated upon their depletion. It can be speculated that these changes alter phagocytic and efferocytic function of neighboring cells, contributing to an altered inflammatory state and, as such, may dampen inflammation. At the same time, CD169 expression, while more restricted to macrophage-lineage cells, does not appear to be limited to specific macrophage populations, is heterogenous among erythroblastic island macrophages (118), and has been found to change under inflammatory conditions (119). Thus, additional tools for targeting and manipulating macrophages in vivo, are required and there is a critical need to identify specific transcriptional networks for bone marrow macrophages.

\section{Macrophages and HSC Relocation}

Mobilized HSCs may not return to the bone marrow and have the potential to migrate to and reside in other tissues. Extramedullary hematopoiesis occurs under physiological conditions, as seen during embryogenesis (24), and in adult tissues, such as the spleen and lung, where pulmonary thrombopoiesis has been observed (120). Extramedullary hematopoiesis may also arise secondary to various pathologic circumstances, such as bone marrow myelofibrosis, cancer, and myocardial infarction. Splenic red pulp macrophages sequester mobilized HSCs in the spleen via the adhesion molecule VCAM-1 following myocardial infarct (121), and these HSCs are monocyte-biased and express the chemokine receptor CCR2. An HSC-intrinsic effect may also contribute to HSC mobilization in this condition as $\sim 15 \%$ of HSCs in bone marrow express the chemokine receptor CCR2 and over $90 \%$ of those found in blood and spleen are CCR2 ${ }^{+}$ suggesting that bone marrow contains a subset of HSCs primed for mobilization via CCR2. As CCR2 ${ }^{+}$HSCs are myeloid biased (122), these data suggest that macrophages in the spleen support a reservoir of HSCs for rapid production and mobilization of myeloid cells, and this may be relevant to a variety of disease conditions.

\section{MACROPHAGES CONTROL DEMAND-ADAPTED HEMATOPOIESIS}

Organisms encounter many different types of stress in a lifetime, but one of the most consistent pressures is the exposure to microbes, many of which are pathogenic. The systemic response to injury and infection is exemplified by demandadapted hematopoiesis, a process of expedited myeloid cell production $(123,124)$. This process of "emergency myelopoiesis" is a response to inflammation elicited either experimentally with sterile PRR agonists or via infection with pathogenic organisms, where myeloid progenitors rapidly proliferate, generating and mobilizing myeloid cells (125). Pro-inflammatory factors including TNF and IL-1 are critical for remodeling the bone marrow, such that resources support myeloid cell production at the expense of lymphopoiesis $(123,126)$. G-CSF signaling results in increased reactive oxygen species promoting emergency granulopoiesis (127). G-CSF drives a profound decrease in medullary macrophages that coincides with an expansion of the granulocytic lineage and their subsequent release, consistent with the observation that neutrophils and HSCs share CXCL12dependent retention mechanisms (128). The role of nonhematopoietic cells in driving emergency myelopoiesis was illustrated by elegant experiments wherein IL-1R responsiveness was restricted to radio-resistant host cells (129). Additional studies determined that TLR4-driven emergency granulopoiesis involved endothelial cells and their ability to respond to LPS (130). As macrophages likely contribute to radio-resistant cells in mouse chimeric studies, it remains to be determined whether macrophages also respond to TLRs and IL-1 in the context of "emergency granulopoiesis."

In response to intracellular pathogens that elicit type II interferon (IFN $\gamma$ ) responses, the acute impact of G-CSFdependent macrophage depletion does not occur, and rather IFN $\gamma$ maintains bone marrow macrophages and drives expedited production of monocytes (131-134). The ability to fine tune myeloid cell production may have evolved to combat different 
types of pathogens; for example, whereas neutrophils are critical for control of extracellular pathogens, monocyte-derived macrophages orchestrate cell-mediated immunity necessary for clearance of intracellular organisms. In the context of acute viral infection, IFN $\gamma$ is necessary to restrict granulopoiesis and prevents viral encephalitis (135). These data suggest that IFN $\gamma$ counters G-CSF-induced depletion of macrophages and would limit HSC/HSPC mobilization. Consistent with this idea, during infection with an intracellular bacterial pathogen that elicits a robust IFN $\gamma$ response, the bone marrow, splenic, and blood pools of HSC/HSPCs are reduced, whereas similar infection in the absence of IFN $\gamma$ or in mice where macrophages cannot respond to IFN $\gamma$ robust HSPC mobilization is observed (113). Additional factors that contribute to the macrophage-mediated myeloid responses will be important to delineate to further our understanding of how demand-adapted hematopoiesis is controlled, and how these responses contribute to host defense and pathogenesis.

Platelets are essential for hemostasis, and these small granulocytes also play vital roles in immunity and inflammatory responses. Platelets are in high demand during acute infection and injury, and low platelet counts, or thrombocytopenia, is a risk factor associated with severe disease in sepsis (136-138). Platelets have the ability to directly trap pathogens $(139,140)$, and control early inflammatory responses to pathogens by regulating the migration, activity, and function of myeloid cells $(141,142)$. The host's ability to rapidly generate platelets in the context of inflammation is likely important for survival. Supporting the crucial role of platelets in immunity are the observations that inflammation can drive expansion of megakaryocyte-primed CD41 ${ }^{\text {hi }}$ stem-like hematopoietic progenitors (143), enhance chemokine-mediated platelet production (144), and promote an altered form of IL-1 receptor-dependent platelet generation via the rupture of megakaryocytes (145). The observation that HSCs with inherent megakaryocyte bias exist at the top of the hematopoietic hierarchy supports the idea that platelets play an essential role in host fitness (146). IL-1 is a highly conserved component of innate immunity and IL- $1 \alpha$ is essential for timely wound healing responses, in part via its ability to increase platelet production (147). Platelets can modulate macrophage function in a variety of settings, and can promote macrophage activation and clearance of bacteria (148-150). At the same time, macrophages can produce a variety of cytokines and chemokines that may act locally as a source of pro-inflammatory factors that influence platelet activity and possibly augment platelet production. Inflammatory conditions can induce expression of podoplanin on macrophages, which was shown to activate platelets in mice via the receptor CLEC-2 (151). Megakaryocytes also express CLEC-2 and signaling via this receptor promotes normal levels of thrombopoietin necessary for HSC maintenance (152). Megakaryocytes are not only the source of platelets but also direct regulators of HSC function and enforce HSC quiescence through production of CXCL4 and TGF $\beta$ (153, 154). As macrophages and megakaryocytes likely share common niches in the marrow it will be important to further understand their interactions, both contact-dependent and independent, and how these interactions impact megakaryopoiesis, thrombopoiesis, and HSC function.

\section{MACROPHAGES IN THE PATHOGENESIS OF BONE MARROW FAILURE SYNDROMES}

Severe aplastic anemia (SAA) is a rare, auto-reactive T celldriven bone marrow failure disease resulting in pancytopenia and accompanied by the loss of HSCs (155-157). Although the direct cause remains unknown, exposure to radiation, chemicals such as benzene and certain pesticides, and infections have been linked to SAA $(158,159)$. Due to numerous clinical overlaps with other blood diseases, SAA diagnosis is often complicated and accomplished via a process of elimination. Inflammation in the bone marrow during SAA is driven by both IFN $\gamma$ and TNF $(157,160,161)$. T cells are important drivers of disease via over-production of IFN $\gamma$, and T cell, derived IFN $\gamma$ promotes Fas-mediated apoptosis of bone marrow cells contributing to bone marrow hypocellularity and loss of HSCs and HSPCs (160, 162, 163). Recent evidence has identified a role for macrophages in SAA pathogenesis [(119, 164); Figure 2]. In a murine model of SAA bone marrow resident macrophages were found to persist during disease despite loss of other myeloid cells (119), consistent with findings from human SAA patients (165). Macrophage persistence was dependent on IFN $\gamma \mathrm{R}$ and $\mathrm{M}$-CSF-R signaling, and disease was associated with emergence of a population of macrophages that express podoplanin (119). Macrophage persistence and dysfunction during SAA correlated with elevated Nos2 expression and a loss of niche cells. Blocking IFN $\gamma$ signaling in macrophages, or depleting macrophages, resulted in a striking but transient increase in platelet-biased CD41 ${ }^{\text {hi }}$ HSCs that corresponded to markedly improved thrombocytopenia and rescued mouse survival. IFN $\gamma$ is known to drive macrophage activation, promoting a proinflammatory phenotype and expression of TNF $(40,166)$. Macrophage-derived TNF was critical for donor T cell infiltration into the bone marrow and T cell secretion of IFN $\gamma$, and TNFproducing macrophages were found to be more abundant in SAA patients compared to healthy controls (164). Moreover, macrophages from SAA patients elicited more robust IFN $\gamma$ responses by co-cultured $\mathrm{T}$ cells. The underlying molecular mechanisms whereby IFN $\gamma$-activated macrophages reduce HSCs may contribute to additional, more targeted therapies to treat SAA. IFN $\gamma$ signaling in macrophages was necessary for increased production of pro-inflammatory beta-chemokines in the bone marrow during SAA (167) and how these chemokine gradients impact HSC location and function will be important to pursue to further understand SAA pathogenesis.

Myelodysplastic syndromes (MDS) are a heterogeneous collection of bone marrow failure diseases characterized by cytopenias, marrow dysplasia, and the expansion of mutationcarrying clones $(168,169)$. MDS is more common in older patients, correlating with the age-related development of clonal hematopoiesis, and much like SAA, marrow failure in MDS is characterized by a unique inflammatory signature including increased TNF, IFN $\gamma$, and cell death in the bone marrow (170, 171). Moreover, inflammasome activation was found to drive MDS demonstrating that cell death mechanisms, specifically pyroptotic cell death, contribute to MDS pathophysiology (172). 


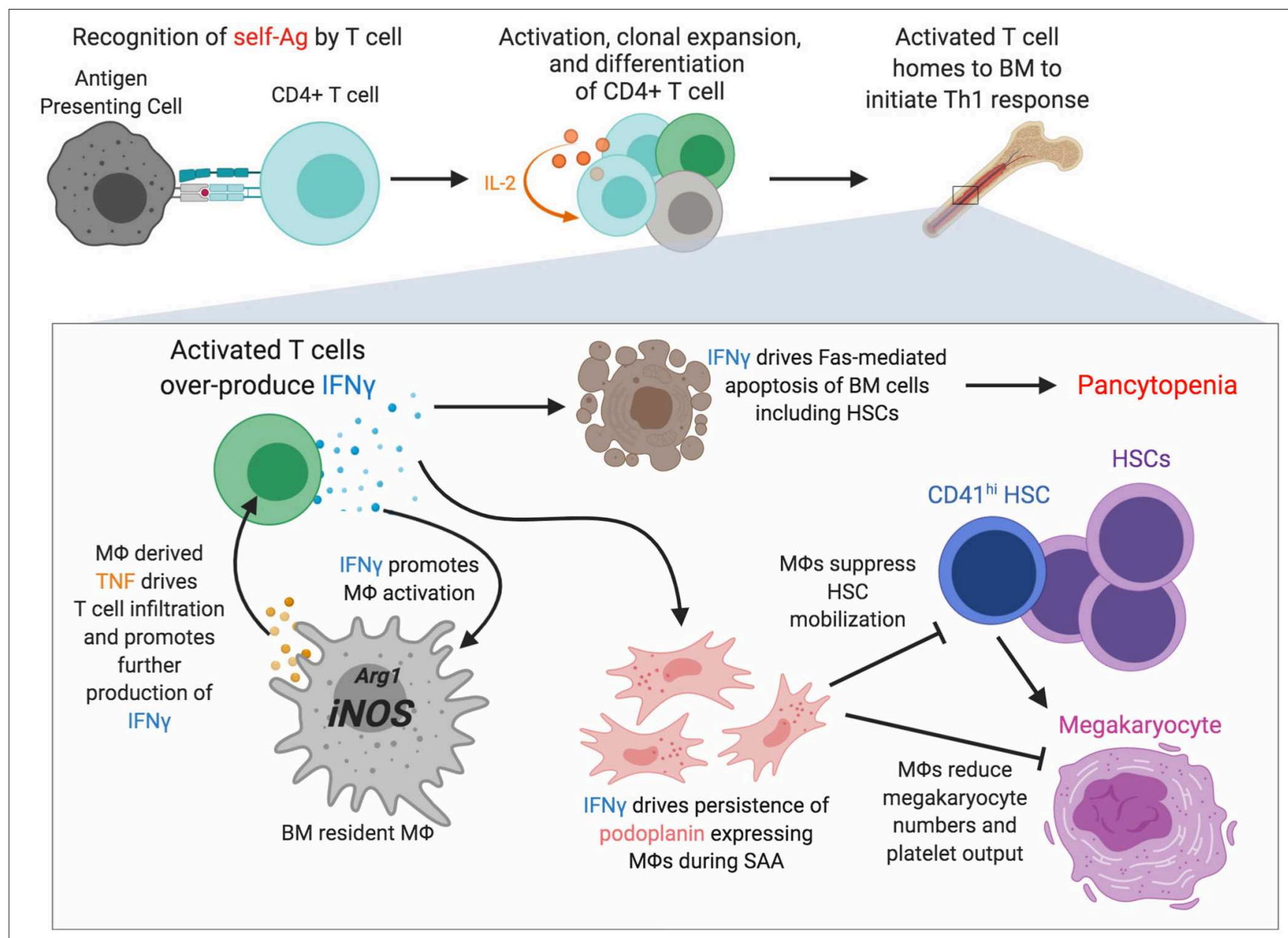

FIGURE 2 | Macrophages are novel regulators of severe aplastic anemia pathogenesis. Recognition of self-antigens by particular T cell clones is thought to initiate severe aplastic anemia (SAA). Activation, clonal expansion mediated by an IL-2 feedback loop, and differentiation of the self-reactive T cell occurs and homing to and accumulation in bone marrow drives a strong Th1 response including overproduction of IFN $\gamma$, an essential driver of disease. IFN $\gamma$ promotes Fas-mediated apoptosis of various bone marrow cells. IFN $\gamma$ also promotes macrophage persistence and activation with increased Nos2 transcription and increased TNF production. IFN $\gamma$ drives the persistence of macrophages that express podoplanin which corresponds with decreased marrow megakaryocytes, reduced numbers of CD41 hi HSCs, and severe thrombocytopenia. Figure generated using BioRender.com.

Consistent with the complex regulation of hematopoiesis by both intrinsic mechanisms and niche-driven mechanisms, the bone marrow microenvironment plays a central role in the development of MDS (173-175). Monocytes from MDS patients were shown to generate macrophages that exhibit increased TNF production and altered phagocytic capacity (176), and dysfunctional macrophages are seen early in MDS and may be an initiating event that allows progression of MDS and leukemia.

Intrinsic drivers of MDS are suggested by the outgrowth of particular clones and numerous mutations have been described and linked with MDS prognosis (177). Ten eleven translocation 2 (TET2) is an epigenetic regulator frequently mutated in clonal hematopoiesis and MDS. Tet2 is the most highly expressed TET enzyme in murine and human macrophages and loss of TET2 results in enhanced $I l 1 b$ and $I l 6$ expression by macrophages in response to LPS stimulation demonstrating its role in controlling inflammation (178). Mutations in Tet2 may alter inflammatory responses in the bone marrow microenvironment thus contributing to HSC dysfunction and clonal hematopoiesis leading to MDS. Tet2-deficient macrophages also exhibit elevated Arg1 expression, which may be a mechanism to combat increased inflammation within the microenvironment (179) while also potentially enhancing the self-renewal and survival of pre-malignant clones. The precise mechanisms whereby macrophages regulate marrow inflammation and regeneration will likely provide insight to SAA and MDS pathophysiology.

\section{MACROPHAGES REGULATE HSC DYSFUNCTION IN AGING}

Normal aging is associated with a spectrum of disorders and increased frailty that correlates with a general escalation of systemic inflammation. Dysfunction of the hematopoietic 
system in aged individuals includes diminished immune responses and weakened host defense, altered lineage output, anemia, clonal hematopoiesis, and increased incidence of myeloid neoplasms all of which are due to combinatorial intrinsic and extrinsic mechanisms [reviewed in $(180,181)]$. In aged animals HSCs exhibit decreased self-renewal, enhanced myeloid and megakaryocytic differentiation, and have reduced homing abilities (182, 183). Dramatic remodeling occurs in the bone marrow of aged animals with an increase in endothelial volume, increased neurovascularization, and reduced collagen, correlating with age-associated bone loss $(184,185)$. HSCs have been shown to relocate to perisinusoidal niches, where they become less quiescent and adopt myeloid/megakaryocyte bias $(184,186)$. In many ways, the low level of inflammation associated with aging recapitulates observations of hematopoietic output seen in acute inflammation, namely reduced lymphopoiesis and enhanced myelopoiesis.

The incidence of bone marrow failure, myeloid cancers, and clonal hematopoiesis increases with age, which suggests a direct relationship between elevated inflammatory signaling and disease progression. Increasing age is also associated with clinical challenges as seen in aged individuals with SAA, where effectiveness of immunosuppressive therapies is greatly diminished and the only curative treatment, HSC transplantation, is associated with increased risk of complications and failure (187). Macrophages are sources of inflammatory molecules and also respond to specific inflammatory factors, such as G-CSF (109), suggesting their potential to influence HSC function and hematopoietic output during aging.

Macrophage dysfunction in aging plays a prominent role in cardiovascular disease, cancer, and autoimmune diseases (188). In the bone marrow, macrophage dysfunction induced plateletbiased HSCs in aged mice (185). Macrophages from aged marrow exhibited a pro-inflammatory transcriptional signature, whereas genes associated with phagocytosis and efferocytosis were markedly reduced (185). The ability of marrow macrophages to clear senescent neutrophils was impaired in aged mice, and reduced phagocytosis corresponded to elevated transcription of pro-inflammatory genes, including Illb. The phagocytic program observed in aging was consistent with studies in young mice that demonstrated cell clearance dampens inflammation and imprints a program of continued clearance (189), thus supporting a direct relationship between increased inflammation and reduced phagocytosis in aging. Moreover, deficiency in Axl recapitulated the age-associated phenotypes. IL-1R signaling is a key driver of inflammation-induced HSC dysfunction (9), and aged marrow macrophages not only expressed elevated $I l 1 b$ transcripts but also contained active caspase 1, necessary for processing active IL-1 $\beta$. It will be important to determine if the impact of IL$1 \mathrm{R}$ signaling on platelet-bias is an HSC-intrinsic mechanism, or if autocrine or paracrine signaling in other cell types is critical for HSC dysfunction and, furthermore, how IL-1R signaling in distinct marrow niches impacts HSC biology. As inflammation can impair efferocytosis and efferocytic activity can dampen inflammation, this circuitry may be a critical target for diminishing inflammation in aging.
Inflammation is a critical driver of overt hematologic dysfunction and is emerging as an underlying driver of clonal expansion in the hematopoietic compartment, and likely other tissues. Clonal hematopoiesis, while not necessarily sufficient to induce hematologic disease, has been demonstrated to impact mortality associated with cardiovascular disease (190). Therefore, understanding the intrinsic and extrinsic cues regulating clonal evolution within the hematopoietic system is broadly relevant to human health. Tet2 loss of function is an important driver of clonal hematopoiesis and studies in mice have demonstrated that Tet2-deficient macrophages accelerated cardiovascular disease (191). Clonal hematopoiesis is interrogated by examining the peripheral blood where variant allele frequencies are most common among myeloid cells. The clonal nature of the marrow microenvironment is an important consideration in understanding how selection and outgrowth occurs, as mature myeloid cells may feedback on the more primitive progenitors through production of inflammatory factors.

\section{SUMMARY AND OPEN QUESTIONS}

Hematopoiesis is a dynamic process that adapts rapidly to inflammatory stress in order to provide cells that are in high demand. The flexibility of this elegant system is necessary for host defense and responses to trauma and injury. The system also has built-in mechanisms to restore homeostasis, though these are not well-understood. Macrophages contribute to the regulation of HSC biology during all stages of life, and it is now established that macrophages control hematopoietic output in health and disease and are critical regulators in diverse pathologic states. However, key questions remain about bone marrow macrophages. Are there inherent differences between embryonically derived and HSC-derived bone marrow macrophages? How are marrow macrophages maintained or replaced in health and in response to inflammation and infection? How does location in the bone marrow impact macrophage function? What are the key signals that promote pathologic macrophage survival? Are macrophages that derive from specific mutant HSC clones more able to self-renew in vivo? Can HSC transplantation be improved via targeting marrow macrophages in some way? Exploring these and other gaps in our understanding may reveal useful insights to our fundamental understanding of HSC biology, but also provide windows of opportunity to reverse disease and maintain healthy macrophages and hematopoiesis throughout life.

\section{AUTHOR CONTRIBUTIONS}

AS, JM, and KM reviewed literature and wrote the manuscript. All authors contributed to the article and approved the submitted version.

\section{FUNDING}

This work was supported by National Institutes of Health funding from NIGMS (R35GM131842) to KM and through a grant from the Department of Defense Bone Marrow Failure Program (BM160071) to KM. 


\section{REFERENCES}

1. Morrison SJ, Scadden DT. The bone marrow niche for haematopoietic stem cells. Nature. (2014) 505:327-34. doi: 10.1038/nature12984

2. Calvi LM, Link DC. The hematopoietic stem cell niche in homeostasis and disease. Blood. (2015) 126:2443-51. doi: 10.1182/blood-2015-07-533588

3. Wilson A, Laurenti E, Oser G, van der Wath RC, Blanco-Bose W, Jaworski $\mathrm{M}$, et al. Hematopoietic stem cells reversibly switch from dormancy to self-renewal during homeostasis and repair. Cell. (2008) 135:111829. doi: 10.1016/j.cell.2008.10.048

4. Sun J, Ramos A, Chapman B, Johnnidis JB, Le L, Ho YJ, et al. Clonal dynamics of native haematopoiesis. Nature. (2014) 514:3227. doi: 10.1038/nature13824

5. Pietras EM, Reynaud D, Kang YA, Carlin D, Calero-Nieto FJ, Leavitt AD, et al. Functionally distinct subsets of lineage-biased multipotent progenitors control blood production in normal and regenerative conditions. Cell Stem Cell. (2015) 17:35-46. doi: 10.1016/j.stem.2015.05.003

6. Kiel MJ, Yilmaz OH, Iwashita T, Yilmaz OH, Terhorst C, Morrison SJ. SLAM family receptors distinguish hematopoietic stem and progenitor cells and reveal endothelial niches for stem cells. Cell. (2005) 121:110921. doi: $10.1016 /$ j.cell.2005.05.026

7. Nagai Y, Garrett KP, Ohta S, Bahrun U, Kouro T, Akira S, et al. Toll-like receptors on hematopoietic progenitor cells stimulate innate immune system replenishment. Immunity. (2006) 24:801-12. doi: 10.1016/j.immuni.2006.04.008

8. Yanez A, Goodridge HS, Gozalbo D, Gil ML. TLRs control hematopoiesis during infection. Eur J Immunol. (2013) 43:252633. doi: 10.1002/eji.201343833

9. Pietras EM, Mirantes-Barbeito C, Fong S, Loeffler D, Kovtonyuk LV, Zhang $S$, et al. Chronic interleukin-1 exposure drives haematopoietic stem cells towards precocious myeloid differentiation at the expense of self-renewal. Nat Cell Biol. (2016) 18:607-18. doi: 10.1038/ncb3346

10. Essers MA, Offner S, Blanco-Bose WE, Waibler Z, Kalinke U, Duchosal MA, et al. IFNalpha activates dormant haematopoietic stem cells in vivo. Nature. (2009) 458:904-8. doi: 10.1038/nature07815

11. Baldridge MT, King KY, Boles NC, Weksberg DC, Goodell MA. Quiescent haematopoietic stem cells are activated by IFN-gamma in response to chronic infection. Nature. (2010) 465:793-7. doi: 10.1038/nature09135

12. Matatall KA, Jeong $\mathrm{M}$, Chen $\mathrm{S}$, Sun $\mathrm{D}$, Chen $\mathrm{F}$, Mo $\mathrm{Q}$, et al. Chronic infection depletes hematopoietic stem cells through stress-induced terminal differentiation. Cell Rep. (2016) 17:2584-95. doi: 10.1016/j.celrep.2016.11.031

13. Matatall KA, Shen CC, Challen GA, King KY. Type II interferon promotes differentiation of myeloid-biased hematopoietic stem cells. Stem Cells. (2014) 32:3023-30. doi: 10.1002/stem.1799

14. Smith JNP, Zhang Y, Li JJ, McCabe A, Jo HJ, Maloney J, et al. Type I IFNs drive hematopoietic stem and progenitor cell collapse via impaired proliferation and increased RIPK1-dependent cell death during shock-like ehrlichial infection. PLoS Pathog. (2018) 14:e1007234. doi: 10.1371/journal.ppat.1007234

15. Davies LC, Jenkins SJ, Allen JE, Taylor PR. Tissue-resident macrophages. Nat Immunol. (2013) 14:986-95. doi: 10.1038/ni.2705

16. Chow A, Brown BD, Merad M. Studying the mononuclear phagocyte system in the molecular age. Nat Rev Immunol. (2011) 11:788-98. doi: 10.1038/nri3087

17. Gordon S. Elie Metchnikoff, the man and the myth. J Innate Immun. (2016) 8:223-7. doi: 10.1159/000443331

18. Ley K, Pramod AB, Croft M, Ravichandran KS, Ting JP. How mouse macrophages sense what is going On. Front Immunol. (2016) 7:204. doi: 10.3389/fimmu.2016.00204

19. Palis J, Robertson S, Kennedy M, Wall C, Keller G. Development of erythroid and myeloid progenitors in the yolk sac and embryo proper of the mouse. Development. (1999) 126:5073-84.

20. Hoeffel G, Chen J, Lavin Y, Low D, Almeida FF, See P, et al. $\mathrm{C}-\mathrm{Myb}(+)$ erythro-myeloid progenitor-derived fetal monocytes give rise to adult tissue-resident macrophages. Immunity. (2015) 42:665-78. doi: 10.1016/j.immuni.2015.03.011

21. McGrath KE, Frame JM, Palis J. Early hematopoiesis and macrophage development. Semin Immunol. (2015) 27:37987. doi: 10.1016/j.smim.2016.03.013
22. Haldar M, Kohyama $M$, So AY, Kc W, Wu X, Briseno CG, et al. Heme-mediated SPI-C induction promotes monocyte differentiation into iron-recycling macrophages. Cell. (2014) 156:1223-34. doi: 10.1016/j.cell.2014.01.069

23. Hoekstra M, Kruijt JK, van Eck M, van Berkel JTC. Specific gene expression of ATP-binding cassette transporters and nuclear hormone receptors in rat liver parenchymal, endothelial, Kupffer cells. J Biol Chem. (2003) 278:2544853. doi: 10.1074/jbc.M301189200

24. Mass E, Ballesteros I, Farlik M, Halbritter F, Gunther P, Crozet L, et al. Specification of tissue-resident macrophages during organogenesis. Science. (2016) 353:aaf4238. doi: 10.1126/science.aaf4238

25. Gautier EL, Shay T, Miller J, Greter M, Jakubzick C, Ivanov S, et al. Immunological genome: gene-expression profiles and transcriptional regulatory pathways that underlie the identity and diversity of mouse tissue macrophages. Nat Immunol. (2012) 13:1118-28. doi: 10.1038/ni.2419

26. Schneider C, Nobs SP, Kurrer M, Rehrauer H, Thiele C, Kopf M. Induction of the nuclear receptor PPAR-gamma by the cytokine GM-CSF is critical for the differentiation of fetal monocytes into alveolar macrophages. Nat Immunol. (2014) 15:1026-37. doi: 10.1038/ni.3005

27. Salei N, Rambichler S, Salvermoser J, Papaioannou NE, Schuchert $\mathrm{R}$, Pakalniskyte $\mathrm{D}$, et al. The kidney contains ontogenetically distinct dendritic cell and macrophage subtypes throughout development that differ in their inflammatory properties. J Am Soc Nephrol. (2020) 31:25778. doi: 10.1681/ASN.2019040419

28. Yamamoto M, Kato T, Hotta C, Nishiyama A, Kurotaki D, Yoshinari $\mathrm{M}$, et al. Shared and distinct functions of the transcription factors IRF4 and IRF8 in myeloid cell development. PLoS ONE. (2011) 6:e25812. doi: 10.1371/journal.pone.0025812

29. Hashimoto D, Chow A, Noizat C, Teo P, Beasley MB, Leboeuf M, et al. Tissue-resident macrophages self-maintain locally throughout adult life with minimal contribution from circulating monocytes. Immunity. (2013) 38:792-804. doi: 10.1016/j.immuni.2013.04.004

30. Liu Z, Gu Y, Chakarov S, Bleriot C, Kwok I, Chen X, et al. Fate mapping via Ms4a3-expression history traces monocyte-derived cells. Cell. (2019) 178:1509-25.e19. doi: 10.1016/j.cell.2019.08.009

31. Gomez Perdiguero E, Klapproth K, Schulz C, Busch K, Azzoni E, Crozet L, et al. Tissue-resident macrophages originate from yolk-sac-derived erythromyeloid progenitors. Nature. (2015) 518:547-51. doi: 10.1038/nature13989

32. Ginhoux F, Guilliams M. Tissue-resident macrophage ontogeny and homeostasis. Immunity. (2016) 44:439-49. doi: 10.1016/j.immuni.2016. 02.024

33. Rantakari P, Jappinen N, Lokka E, Mokkala E, Gerke H, Peuhu E, et al. Fetal liver endothelium regulates the seeding of tissue-resident macrophages. Nature. (2016) 538:392-6. doi: 10.1038/nature19814

34. Stan RV, Tse D, Deharvengt SJ, Smits NC, Xu Y, Luciano MR, et al. The diaphragms of fenestrated endothelia: gatekeepers of vascular permeability and blood composition. Dev Cell. (2012) 23:1203-18. doi: 10.1016/j.devcel.2012.11.003

35. Scott CL, Zheng F, De Baetselier P, Martens L, Saeys Y, De Prijck S, et al. Bone marrow-derived monocytes give rise to self-renewing and fully differentiated Kupffer cells. Nat Commun. (2016) 7:10321. doi: 10.1038/ncomms10321

36. Heidt T, Courties G, Dutta P, Sager HB, Sebas M, Iwamoto Y, et al. Differential contribution of monocytes to heart macrophages in steady-state and after myocardial infarction. Circ Res. (2014) 115:28495. doi: 10.1161/CIRCRESAHA.115.303567

37. Machiels B, Dourcy M, Xiao X, Javaux J, Mesnil C, Sabatel C, et al. A gammaherpesvirus provides protection against allergic asthma by inducing the replacement of resident alveolar macrophages with regulatory monocytes. Nat Immunol. (2017) 18:1310-20. doi: 10.1038/ni.3857

38. Dietrich J, Baryawno N, Nayyar N, Valtis YK, Yang B, Ly I, et al. Bone marrow drives central nervous system regeneration after radiation injury. J Clin Invest. (2018) 128:281-93. doi: 10.1172/JCI121592

39. Mosser DM. The many faces of macrophage activation. J Leukoc Biol. (2003) 73:209-12. doi: 10.1189/jlb.0602325

40. Orecchioni M, Ghosheh Y, Pramod AB, Ley K. Macrophage polarization: different gene signatures in M1(LPS+) vs Classically and M2(LPS-) vs alternatively activated macrophages. Front Immunol. (2019) 10:1084. doi: 10.3389/fimmu.2019.01084

41. Mantovani A, Sica A, Locati M. Macrophage polarization comes of age. Immunity. (2005) 23:344-6. doi: 10.1016/j.immuni.2005.10.001 
42. Mantovani A, Locati M. Orchestration of macrophage polarization. Blood. (2009) 114:3135-6. doi: 10.1182/blood-2009-07-231795

43. Jenkins SJ, Ruckerl D, Cook PC, Jones LH, Finkelman FD, van Rooijen $\mathrm{N}$, et al. Local macrophage proliferation, rather than recruitment from the blood, is a signature of TH2 inflammation. Science. (2011) 332:12848. doi: 10.1126/science. 1204351

44. Morioka S, Maueroder C, Ravichandran KS. Living on the edge: efferocytosis at the interface of homeostasis and pathology. Immunity. (2019) 50:114962. doi: 10.1016/j.immuni.2019.04.018

45. Kobayashi N, Karisola P, Pena-Cruz V, Dorfman DM, Jinushi M, Umetsu SE, et al. TIM-1 and TIM-4 glycoproteins bind phosphatidylserine and mediate uptake of apoptotic cells. Immunity. (2007) 27:92740. doi: 10.1016/j.immuni.2007.11.011

46. Elliott MR, Koster KM, Murphy PS. Efferocytosis signaling in the regulation of macrophage inflammatory responses. J Immunol. (2017) 198:138794. doi: 10.4049/jimmunol.1601520

47. Rothlin CV, Ghosh S, Zuniga EI, Oldstone MB, Lemke G. TAM receptors are pleiotropic inhibitors of the innate immune response. Cell. (2007) 131:112436. doi: 10.1016/j.cell.2007.10.034

48. Camenisch TD, Koller BH, Earp HS, Matsushima GK. A novel receptor tyrosine kinase, Mer, inhibits TNF-alpha production and lipopolysaccharideinduced endotoxic shock. J Immunol. (1999) 162:3498-503.

49. Doran AC, Ozcan L, Cai B, Zheng Z, Fredman G, Rymond CC, et al. CAMKIIgamma suppresses an efferocytosis pathway in macrophages and promotes atherosclerotic plaque necrosis. J Clin Invest. (2017) 127:407589. doi: 10.1172/JCI94735

50. Cai B, Thorp EB, Doran AC, Subramanian M, Sansbury BE, Lin CS, et al. MerTK cleavage limits proresolving mediator biosynthesis and exacerbates tissue inflammation. Proc Natl Acad Sci USA. (2016) 113:652631. doi: 10.1073/pnas.1524292113

51. Bosurgi L, Bernink JH, Delgado Cuevas V, Gagliani N, Joannas L, Schmid ET, et al. Paradoxical role of the proto-oncogene Axl and Mer receptor tyrosine kinases in colon cancer. Proc Natl Acad Sci USA. (2013) 110:130916. doi: 10.1073/pnas.1302507110

52. Anwar A, Keating AK, Joung D, Sather S, Kim GK, Sawczyn KK, et al. Mer tyrosine kinase (MerTK) promotes macrophage survival following exposure to oxidative stress. J Leukoc Biol. (2009) 86:73-9. doi: 10.1189/jlb.06 08334

53. Nishi C, Yanagihashi Y, Segawa K, Nagata S. MERTK tyrosine kinase receptor together with TIM4 phosphatidylserine receptor mediates distinct signal transduction pathways for efferocytosis and cell proliferation. J Biol Chem. (2019) 294:7221-30. doi: 10.1074/jbc.RA118.006628

54. Knubel KH, Pernu BM, Sufit A, Nelson S, Pierce AM, Keating AK. MerTK inhibition is a novel therapeutic approach for glioblastoma multiforme. Oncotarget. (2014) 5:1338-51. doi: 10.18632/oncotarget.1793

55. Kauts ML, Vink CS, Dzierzak E. Hematopoietic (stem) cell development - how divergent are the roads taken? FEBS Lett. (2016) 590:397586. doi: 10.1002/1873-3468.12372

56. Cunningham CL, Martinez-Cerdeno V, Noctor SC. Microglia regulate the number of neural precursor cells in the developing cerebral cortex. $J$ Neurosci. (2013) 33:4216-33. doi: 10.1523/JNEUROSCI.3441-12.2013

57. Medvinsky A, Dzierzak E. Definitive hematopoiesis is autonomously initiated by the AGM region. Cell. (1996) 86:897-906. doi: 10.1016/S0092-8674(00)80165-8

58. de Bruijn MF, Ma X, Robin C, Ottersbach K, Sanchez MJ, Dzierzak E. Hematopoietic stem cells localize to the endothelial cell layer in the midgestation mouse aorta. Immunity. (2002) 16:673-83. doi: 10.1016/S1074-7613(02)00313-8

59. Benz C, Copley MR, Kent DG, Wohrer S, Cortes A, Aghaeepour N, et al. Hematopoietic stem cell subtypes expand differentially during development and display distinct lymphopoietic programs. Cell Stem Cell. (2012) 10:27383. doi: $10.1016 /$ j.stem.2012.02.007

60. Li Y, Esain V, Teng L, Xu J, Kwan W, Frost IM, et al. Inflammatory signaling regulates embryonic hematopoietic stem and progenitor cell production. Genes Dev. (2014) 28:2597-612. doi: 10.1101/gad.253302.114

61. Rae F, Woods K, Sasmono T, Campanale N, Taylor D, Ovchinnikov DA, et al. Characterisation and trophic functions of murine embryonic macrophages based upon the use of a Csf1r-EGFP transgene reporter. Dev Biol. (2007) 308:232-46. doi: 10.1016/j.ydbio.2007.05.027
62. Travnickova J, Tran Chau V, Julien E, Mateos-Langerak J, Gonzalez C, Lelievre E, et al. Primitive macrophages control HSPC mobilization and definitive haematopoiesis. Nat Commun. (2015) 6:6227. doi: $10.1038 /$ ncomms7227

63. Mariani SA, Li Z, Rice S, Krieg C, Fragkogianni S, Robinson M, et al. Pro-inflammatory aorta-associated macrophages are involved in embryonic development of hematopoietic stem cells. Immunity. (2019) 50:143952.e5. doi: 10.1016/j.immuni.2019.05.003

64. Kaur S, Raggatt LJ, Batoon L, Hume DA, Levesque JP, Pettit AR. Role of bone marrow macrophages in controlling homeostasis and repair in bone and bone marrow niches. Semin Cell Dev Biol. (2017) 61:1221. doi: 10.1016/j.semcdb.2016.08.009

65. Calvi LM, Adams GB, Weibrecht KW, Weber JM, Olson DP, Knight MC, et al. Osteoblastic cells regulate the haematopoietic stem cell niche. Nature. (2003) 425:841-6. doi: 10.1038/nature02040

66. Ding L, Saunders TL, Enikolopov G, Morrison SJ. Endothelial and perivascular cells maintain haematopoietic stem cells. Nature. (2012) 481:457-62. doi: 10.1038/nature10783

67. Greenbaum A, Hsu YM, Day RB, Schuettpelz LG, Christopher MJ, Borgerding JN, et al. CXCL12 in early mesenchymal progenitors is required for haematopoietic stem-cell maintenance. Nature. (2013) 495:22730. doi: 10.1038/nature11926

68. Nie Y, Han YC, Zou YR. CXCR4 is required for the quiescence of primitive hematopoietic cells. J Exp Med. (2008) 205:77783. doi: 10.1084 /jem. 20072513

69. Chow A, Lucas D, Hidalgo A, Mendez-Ferrer S, Hashimoto D, Scheiermann $\mathrm{C}$, et al. Bone marrow CD169+ macrophages promote the retention of hematopoietic stem and progenitor cells in the mesenchymal stem cell niche. J Exp Med. (2011) 208:261-71. doi: 10.1084/jem.20101688

70. McCabe A, MacNamara KC. Macrophages: key regulators of steadystate and demand-adapted hematopoiesis. Exp Hematol. (2016) 44:21322. doi: 10.1016/j.exphem.2016.01.003

71. Udagawa N, Takahashi N, Akatsu T, Tanaka H, Sasaki T, Nishihara T, et al. Origin of osteoclasts: mature monocytes and macrophages are capable of differentiating into osteoclasts under a suitable microenvironment prepared by bone marrow-derived stromal cells. Proc Natl Acad Sci USA. (1990) 87:7260-4. doi: 10.1073/pnas.87.18.7260

72. Lacey DL, Timms E, Tan HL, Kelley MJ, Dunstan CR, Burgess T, et al. Osteoprotegerin ligand is a cytokine that regulates osteoclast differentiation and activation. Cell. (1998) 93:165-76. doi: 10.1016/S0092-8674(00)81569-X

73. Gong L, Zhao Y, Zhang Y, Ruan Z. The macrophage polarization regulates MSC osteoblast differentiation in vitro. Ann Clin Lab Sci. (2016) 46:65-71.

74. Chang MK, Raggatt LJ, Alexander KA, Kuliwaba JS, Fazzalari NL, Schroder $\mathrm{K}$, et al. Osteal tissue macrophages are intercalated throughout human and mouse bone lining tissues and regulate osteoblast function in vitro and in vivo. J Immunol. (2008) 181:1232-44. doi: 10.4049/jimmunol.181.2.1232

75. Chang KH, Sengupta A, Nayak RC, Duran A, Lee SJ, Pratt RG, et al. p62 is required for stem cell/progenitor retention through inhibition of IKK/NFkappaB/Ccl4 signaling at the bone marrow macrophage-osteoblast niche. Cell Rep. (2014) 9:2084-97. doi: 10.1016/j.celrep.2014.11.031

76. Mohamad SF, Xu L, Ghosh J, Childress PJ, Abeysekera I, Himes ER, et al. Osteomacs interact with megakaryocytes and osteoblasts to regulate murine hematopoietic stem cell function. Blood Adv. (2017) 1:252028. doi: 10.1182/bloodadvances.2017011304

77. Chasis JA, Mohandas N. Erythroblastic islands: niches for erythropoiesis. Blood. (2008) 112:470-8. doi: 10.1182/blood-2008-03-077883

78. Giger KM, Kalfa TA. Phylogenetic and ontogenetic view of erythroblastic Islands. Biomed Res Int. (2015) 2015:873628. doi: 10.1155/2015/873628

79. Li W, Wang $\mathrm{Y}$, Zhao $\mathrm{H}$, Zhang $\mathrm{H}, \mathrm{Xu} \mathrm{Y}$, Wang $\mathrm{S}$, et al. Identification and transcriptome analysis of erythroblastic island macrophages. Blood. (2019) 134:480-91. doi: 10.1182/blood.2019000430

80. Yoshida H, Kawane K, Koike M, Mori Y, Uchiyama Y, Nagata S. Phosphatidylserine-dependent engulfment by macrophages of nuclei from erythroid precursor cells. Nature. (2005) 437:7548. doi: 10.1038/nature03964

81. McGrath KE, Kingsley PD, Koniski AD, Porter RL, Bushnell TP, Palis J. Enucleation of primitive erythroid cells generates a transient population of "pyrenocytes" in the mammalian fetus. Blood. (2008) 111:240917. doi: 10.1182/blood-2007-08-107581 
82. Koury MJ, Bondurant MC. Maintenance by erythropoietin of viability and maturation of murine erythroid precursor cells. J Cell Physiol. (1988) 137:6574. doi: 10.1002/jcp.1041370108

83. Brines M, Patel NS, Villa P, Brines C, Mennini T, De Paola M, et al. Nonerythropoietic, tissue-protective peptides derived from the tertiary structure of erythropoietin. Proc Natl Acad Sci USA. (2008) 105:1092530. doi: 10.1073/pnas.0805594105

84. Lifshitz L, Tabak G, Gassmann M, Mittelman M, Neumann D. Macrophages as novel target cells for erythropoietin. Haematologica. (2010) 95:182331. doi: 10.3324/haematol.2010.025015

85. Luo B, Wang J, Liu Z, Shen Z, Shi R, Liu YQ, et al. Phagocyte respiratory burst activates macrophage erythropoietin signalling to promote acute inflammation resolution. Nat Commun. (2016) 7:12177. doi: $10.1038 /$ ncomms 12177

86. Nairz M, Schroll A, Moschen AR, Sonnweber T, Theurl M, Theurl I, et al. Erythropoietin contrastingly affects bacterial infection and experimental colitis by inhibiting nuclear factor-kappaB-inducible immune pathways. Immunity. (2011) 34:61-74. doi: 10.1016/j.immuni.2011.01.002

87. Luo B, Gan W, Liu Z, Shen Z, Wang J, Shi R, et al. Erythropoeitin signaling in macrophages promotes dying cell clearance and immune tolerance. Immunity. (2016) 44:287-302. doi: 10.1016/j.immuni.2016.01.002

88. McArthur GA, Longmore GD, Klingler K, Johnson GR. Lineage-restricted recruitment of immature hematopoietic progenitor cells in response to Epo after normal hematopoietic cell transfection with EpoR. Exp Hematol. (1995) 23:645-54.

89. Pharr PN, Ogawa M, Hofbauer A, Longmore GD. Expression of an activated erythropoietin or a colony-stimulating factor 1 receptor by pluripotent progenitors enhances colony formation but does not induce differentiation. Proc Natl Acad Sci USA. (1994) 91:7482-6. doi: 10.1073/pnas.91.1 6.7482

90. Longmore GD, Pharr PN, Lodish HF. A constitutively activated erythropoietin receptor stimulates proliferation and contributes to transformation of multipotent, committed nonerythroid and erythroid progenitor cells. Mol Cell Biol. (1994) 14:226677. doi: 10.1128/MCB.14.4.2266

91. Comazzetto S, Murphy MM, Berto S, Jeffery E, Zhao Z, Morrison SJ. Restricted hematopoietic progenitors and erythropoiesis require SCF from leptin receptor+ Niche cells in the bone marrow. Cell Stem Cell. (2019) 24:477-86.e6. doi: 10.1016/j.stem.2018.11.022

92. Ludin A, Itkin T, Gur-Cohen S, Mildner A, Shezen E, Golan K, et al. Monocytes-macrophages that express alpha-smooth muscle actin preserve primitive hematopoietic cells in the bone marrow. Nat Immunol. (2012) 13:1072-82. doi: 10.1038/ni.2408

93. Hoggatt J, Singh P, Sampath J, Pelus LM. Prostaglandin E2 enhances hematopoietic stem cell homing, survival, and proliferation. Blood. (2009) 113:5444-55. doi: 10.1182/blood-2009-01-201335

94. Hur J, Choi JI, Lee H, Nham P, Kim TW, Chae CW, et al. CD82/KAI1 maintains the dormancy of long-term hematopoietic stem cells through interaction with DARC-expressing macrophages. Cell Stem Cell. (2016) 18:508-21. doi: 10.1016/j.stem.2016.01.013

95. Lin KK, Rossi L, Boles NC, Hall BE, George TC, Goodell MA. CD81 is essential for the re-entry of hematopoietic stem cells to quiescence following stress-induced proliferation via deactivation of the Akt pathway. PLoS Biol. (2011) 9:e1001148. doi: 10.1371/journal.pbio.1001148

96. Meny GM. The Duffy blood group system: a review. Immunohematology. (2010) 26:51-6.

97. Luo Y, Shao L, Chang J, Feng W, Liu YL, Cottler-Fox MH, et al. M1 and M2 macrophages differentially regulate hematopoietic stem cell self-renewal and ex vivo expansion. Blood Adv. (2018) 2:859870. doi: 10.1182/bloodadvances.2018015685

98. Massberg S, Schaerli P, Knezevic-Maramica I, Kollnberger M, Tubo N, Moseman EA, et al. Immunosurveillance by hematopoietic progenitor cells trafficking through blood, lymph, peripheral tissues. Cell. (2007) 131:9941008. doi: 10.1016/j.cell.2007.09.047

99. Mendez-Ferrer S, Lucas D, Battista M, Frenette PS. Haematopoietic stem cell release is regulated by circadian oscillations. Nature. (2008) 452:4427. doi: 10.1038/nature06685

100. Furze RC, Rankin SM. The role of the bone marrow in neutrophil clearance under homeostatic conditions in the mouse. FASEB J. (2008) 22:31119. doi: 10.1096/fj.08-109876
101. Casanova-Acebes M, Pitaval C, Weiss LA, Nombela-Arrieta C, Chevre R, A-González, $\mathrm{N}$, et al. Rhythmic modulation of the hematopoietic niche through neutrophil clearance. Cell. (2013) 153:1025-35. doi: 10.1016/j.cell.2013.04.040

102. Singh P, Hu P, Hoggatt J, Moh A, Pelus LM. Expansion of bone marrow neutrophils following G-CSF administration in mice results in osteolineage cell apoptosis and mobilization of hematopoietic stem and progenitor cells. Leukemia. (2012) 26:2375-83. doi: 10.1038/leu.2012.117

103. Cain DW, Snowden PB, Sempowski GD, Kelsoe G. Inflammation triggers emergency granulopoiesis through a density-dependent feedback mechanism. PLoS ONE. (2011) 6:e19957. doi: 10.1371/journal.pone.0019957

104. Levesque JP, Hendy J, Takamatsu Y, Simmons PJ, Bendall LJ. Disruption of the CXCR4/CXCL12 chemotactic interaction during hematopoietic stem cell mobilization induced by GCSF or cyclophosphamide. J Clin Invest. (2003) 111:187-96. doi: 10.1172/JCI15994

105. Aiuti A, Webb IJ, Bleul C, Springer T, Gutierrez-Ramos JC. The chemokine SDF-1 is a chemoattractant for human CD34+ hematopoietic progenitor cells and provides a new mechanism to explain the mobilization of CD34+ progenitors to peripheral blood. J Exp Med. (1997) 185:11120. doi: 10.1084/jem.185.1.111

106. Bendall LJ, Bradstock KF. G-CSF: from granulopoietic stimulant to bone marrow stem cell mobilizing agent. Cytokine Growth Factor Rev. (2014) 25:355-67. doi: 10.1016/j.cytogfr.2014.07.011

107. Semerad CL, Christopher MJ, Liu F, Short B, Simmons PJ, Winkler I, et al. G-CSF potently inhibits osteoblast activity and CXCL12 mRNA expression in the bone marrow. Blood. (2005) 106:3020-7. doi: 10.1182/blood-2004-01-0272

108. Liu F, Poursine-Laurent J, Link DC. Expression of the GCSF receptor on hematopoietic progenitor cells is not required for their mobilization by G-CS. Blood. (2000) 95:302531. doi: 10.1182/blood.V95.10.3025.010k32_3025_3031

109. Christopher MJ, Rao M, Liu F, Woloszynek JR, Link DC. Expression of the G-CSF receptor in monocytic cells is sufficient to mediate hematopoietic progenitor mobilization by G-CSF in mice. J Exp Med. (2011) 208:25160. doi: 10.1084/jem.20101700

110. Jacobsen RN, Forristal CE, Raggatt LJ, Nowlan B, Barbier V, Kaur S, et al. Mobilization with granulocyte colony-stimulating factor blocks medullar erythropoiesis by depleting F4/80(+)VCAM1(+)CD169(+)ERHR3 $(+)$ Ly6G $(+)$ erythroid island macrophages in the mouse. Exp Hematol. (2014) 42:547-61.e4. doi: 10.1016/j.exphem.2014.03.009

111. Winkler IG, Pettit AR, Raggatt LJ, Jacobsen RN, Forristal CE, Barbier V, et al. Hematopoietic stem cell mobilizing agents G-CSF, cyclophosphamide or AMD3100 have distinct mechanisms of action on bone marrow HSC niches and bone formation. Leukemia. (2012) 26:1594-601. doi: 10.1038/leu.2012.17

112. Winkler IG, Sims NA, Pettit AR, Barbier V, Nowlan B, Helwani F, et al. Bone marrow macrophages maintain hematopoietic stem cell (HSC) niches and their depletion mobilizes HSCs. Blood. (2010) 116:481528. doi: 10.1182/blood-2009-11-253534

113. McCabe A, Zhang Y, Thai V, Jones M, Jordan MB, MacNamara KC Macrophage-lineage cells negatively regulate the hematopoietic stem cell pool in response to interferon gamma at steady state and during infection. Stem Cells. (2015) 33:2294-305. doi: 10.1002/stem.2040

114. Kaur S, Raggatt LJ, Millard SM, Wu AC, Batoon L, Jacobsen RN, et al. Self-repopulating recipient bone marrow resident macrophages promote long-term hematopoietic stem cell engraftment. Blood. (2018) 132:73549. doi: 10.1182/blood-2018-01-829663

115. Hashimoto D, Chow A, Greter M, Saenger Y, Kwan WH, Leboeuf M, et al. Pretransplant CSF-1 therapy expands recipient macrophages and ameliorates GVHD after allogeneic hematopoietic cell transplantation. J Exp Med. (2011) 208:1069-82. doi: 10.1084/jem.20101709

116. Li Z, Xu X, Feng X, Murphy PM. The macrophage-depleting agent clodronate promotes durable hematopoietic chimerism and donor-specific skin allograft tolerance in mice. Sci Rep. (2016) 6:22143. doi: 10.1038/srep22143

117. Lehenkari PP, Kellinsalmi M, Napankangas JP, Ylitalo KV, Monkkonen J, Rogers MJ, et al. Further insight into mechanism of action of clodronate: inhibition of mitochondrial ADP/ATP translocase by a nonhydrolyzable, adenine-containing metabolite. Mol Pharmacol. (2002) 61:1255-62. doi: 10.1124/mol.61.5.1255 
118. Seu KG, Papoin J, Fessler R, Hom J, Huang G, Mohandas N, et al. Unraveling macrophage heterogeneity in erythroblastic Islands. Front Immunol. (2017) 8:1140. doi: 10.3389/fimmu.2017.01140

119. McCabe A, Smith JNP, Costello A, Maloney J, Katikaneni D, MacNamara KC. Hematopoietic stem cell loss and hematopoietic failure in severe aplastic anemia is driven by macrophages and aberrant podoplanin expression. Haematologica. (2018) 103:1451-61. doi: 10.3324/haematol.2018.189449

120. Lefrancais E, Ortiz-Munoz G, Caudrillier A, Mallavia B, Liu F, Sayah DM, et al. The lung is a site of platelet biogenesis and a reservoir for haematopoietic progenitors. Nature. (2017) 544:105-9. doi: 10.1038/nature21706

121. Dutta P, Hoyer FF, Grigoryeva LS, Sager HB, Leuschner F, Courties G, et al. Macrophages retain hematopoietic stem cells in the spleen via VCAM-1. J Exp Med. (2015) 212:497-512. doi: 10.1084/jem.20141642

122. Dutta P, Sager HB, Stengel KR, Naxerova K, Courties G, Saez $\mathrm{B}$, et al. Myocardial infarction activates CCR2 $(+)$ hematopoietic stem and progenitor cells. Cell Stem Cell. (2015) 16:47787. doi: 10.1016/j.stem.2015.04.008

123. Ueda Y, Kondo M, Kelsoe G. Inflammation and the reciprocal production of granulocytes and lymphocytes in bone marrow. J Exp Med. (2005) 201:177180. doi: 10.1084/jem.20041419

124. Hirai H, Zhang P, Dayaram T, Hetherington CJ, Mizuno S, Imanishi J, et al. $\mathrm{C} / \mathrm{EBPb}$ ta is required for 'emergency' granulopoiesis. Nat Immunol. (2006) 7:732-9. doi: 10.1038/ni1354

125. Takizawa H, Boettcher S, Manz MG. Demand-adapted regulation of early hematopoiesis in infection and inflammation. Blood. (2012) 119:29913002. doi: 10.1182/blood-2011-12-380113

126. Ueda Y, Yang K, Foster SJ, Kondo M, Kelsoe G. Inflammation controls B lymphopoiesis by regulating chemokine CXCL12 expression. J Exp Med. (2004) 199:47-58. doi: 10.1084/jem.20031104

127. Kwak HJ, Liu P, Bajrami B, Xu Y, Park SY, Nombela-Arrieta C, et al. Myeloid cell-derived reactive oxygen species externally regulate the proliferation of myeloid progenitors in emergency granulopoiesis. Immunity. (2015) 42:15971. doi: 10.1016/j.immuni.2014.12.017

128. Eash KJ, Means JM, White DW, Link DC. CXCR4 is a key regulator of neutrophil release from the bone marrow under basal and stress granulopoiesis conditions. Blood. (2009) 113:4711-9. doi: 10.1182/blood-2008-09-177287

129. Ueda Y, Cain DW, Kuraoka M, Kondo M, Kelsoe G. IL-1R type Idependent hemopoietic stem cell proliferation is necessary for inflammatory granulopoiesis and reactive neutrophilia. J Immunol. (2009) 182:647784. doi: 10.4049/jimmunol.0803961

130. Boettcher S, Ziegler P, Schmid MA, Takizawa H, van Rooijen N, Kopf $\mathrm{M}$, et al. Cutting edge: LPS-induced emergency myelopoiesis depends on TLR4-expressing nonhematopoietic cells. J Immunol. (2012) 188:58248. doi: 10.4049/jimmunol.1103253

131. Serbina NV, Hohl TM, Cherny M, Pamer EG. Selective expansion of the monocytic lineage directed by bacterial infection. J Immunol. (2009) 183:1900-10. doi: 10.4049/jimmunol.0900612

132. Zhang Y, Jones M, McCabe A, Winslow GM, Avram D, MacNamara KC. MyD88 signaling in CD4 $\mathrm{T}$ cells promotes IFN-gamma production and hematopoietic progenitor cell expansion in response to intracellular bacterial infection. J Immunol. (2013) 190:4725-35. doi: 10.4049/jimmunol.1203024

133. MacNamara KC, Oduro K, Martin O, Jones DD, McLaughlin M, Choi K, et al. Infection-induced myelopoiesis during intracellular bacterial infection is critically dependent upon IFN-gamma signaling. J Immunol. (2011) 186:1032-43. doi: 10.4049/jimmunol.1001893

134. de Bruin M, Libregts SF, Valkhof $M$, Boon L, Touw IP, Nolte MA. IFNgamma induces monopoiesis and inhibits neutrophil development during inflammation. Blood. (2012) 119:154354. doi: 10.1182/blood-2011-07-367706

135. Ramakrishna C, Cantin EM. IFNgamma inhibits G-CSF induced neutrophil expansion and invasion of the CNS to prevent viral encephalitis. PLoS Pathog. (2018) 14:e1006822. doi: 10.1371/journal.ppat.1006822

136. de Stoppelaar SF, van't Veer C, Claushuis TA, Albersen BJ, Roelofs JJ, van der Poll T. Thrombocytopenia impairs host defense in gramnegative pneumonia-derived sepsis in mice. Blood. (2014) 124:378190. doi: 10.1182/blood-2014-05-573915
137. Claushuis TA, van Vught LA, Scicluna BP, Wiewel MA, Klein Klouwenberg PM, Hoogendijk AJ, et al. Risk stratification of sepsis: thrombocytopenia is associated with a dysregulated host response in critically ill sepsis patients. Blood. (2016) 127:3062-72. doi: 10.1182/blood-2015-11-680744

138. Vanderschueren S, de Weerdt A, Malbrain M, Vankersschaever D, Frans E, Wilmer A, et al. Thrombocytopenia and prognosis in intensive care. Crit Care Med. (2000) 28:1871-6. doi: 10.1097/00003246-200006000-00031

139. Gaertner F, Ahmad Z, Rosenberger G, Fan S, Nicolai L, Busch B, et al. Migrating platelets are mechano-scavengers that collect and bundle bacteria. Cell. (2017) 171:1368-82.e23. doi: 10.1016/j.cell.2017.11.001

140. Wong CH, Jenne CN, Petri B, Chrobok NL, Kubes P. Nucleation of platelets with blood-borne pathogens on Kupffer cells precedes other innate immunity and contributes to bacterial clearance. Nat Immunol. (2013) 14:785-92. doi: 10.1038/ni.2631

141. Nagata K, Tsuji T, Todoroki N, Katagiri Y, Tanoue K, Yamazaki H, et al. Activated platelets induce superoxide anion release by monocytes and neutrophils through P-selectin (CD62). J Immunol. (1993) 151:3267-73.

142. Kornerup KN, Salmon GP, Pitchford SC, Liu WL, Page CP. Circulating platelet-neutrophil complexes are important for subsequent neutrophil activation and migration. J Appl Physiol. (2010) 109:758-67. doi: 10.1152/japplphysiol.01086.2009

143. Haas S, Hansson J, Klimmeck D, Loeffler D, Velten L, Uckelmann $\mathrm{H}$, et al. Inflammation-Induced emergency megakaryopoiesis driven by hematopoietic stem cell-like megakaryocyte progenitors. Cell Stem Cell. (2015) 17:422-34. doi: 10.1016/j.stem.2015.07.007

144. Machlus KR, Johnson KE, Kulenthirarajan R, Forward JA, Tippy MD, Soussou TS, et al. CCL5 derived from platelets increases megakaryocyte proplatelet formation. Blood. (2016) 127:921-6. doi: 10.1182/blood-2015-05-644583

145. Nishimura S, Nagasaki M, Kunishima S, Sawaguchi A, Sakata A, Sakaguchi $\mathrm{H}$, et al. IL-1alpha induces thrombopoiesis through megakaryocyte rupture in response to acute platelet needs. J Cell Biol. (2015) 209:45366. doi: $10.1083 /$ jcb. 201410052

146. Sanjuan-Pla A, Macaulay IC, Jensen CT, Woll PS, Luis TC, Mead A, et al. Platelet-biased stem cells reside at the apex of the haematopoietic stem-cell hierarchy. Nature. (2013) 502:232-6. doi: 10.1038/nature 12495

147. Burzynski LC, Humphry M, Pyrillou K, Wiggins KA, Chan JNE, Figg N, et al. The coagulation and immune systems are directly linked through the activation of interleukin-1alpha by thrombin. Immunity. (2019) 50:103342.e6. doi: 10.1016/j.immuni.2019.03.003

148. Scull CM, Hays WD, Fischer TH. Macrophage pro-inflammatory cytokine secretion is enhanced following interaction with autologous platelets. $J$ Inflamm. (2010) 7:53. doi: 10.1186/1476-9255-7-53

149. Carestia A, Mena HA, Olexen CM, Ortiz Wilczynski JM, Negrotto S, Errasti AE, et al. Platelets promote macrophage polarization toward proinflammatory phenotype and increase survival of septic mice. Cell Rep. (2019) 28:896-908.e5. doi: 10.1016/j.celrep.2019.06.062

150. Ali RA, Wuescher LM, Dona KR, Worth RG. Platelets mediate host defense against Staphylococcus aureus through direct bactericidal activity and by enhancing macrophage activities. J Immunol. (2017) 198:34451. doi: 10.4049/jimmunol.1601178

151. Kerrigan AM, Navarro-Nunez L, Pyz E, Finney BA, Willment JA, Watson SP, et al. Podoplanin-expressing inflammatory macrophages activate murine platelets via CLEC-2. J Thromb Haemost. (2012) 10:4846. doi: 10.1111/j.1538-7836.2011.04614.x

152. Nakamura-Ishizu A, Takubo K, Kobayashi H, Suzuki-Inoue K, Suda T. CLEC-2 in megakaryocytes is critical for maintenance of hematopoietic stem cells in the bone marrow. J Exp Med. (2015) 212:2133-46. doi: 10.1084/jem.20150057

153. Bruns I, Lucas D, Pinho S, Ahmed J, Lambert MP, Kunisaki Y, et al. Megakaryocytes regulate hematopoietic stem cell quiescence through CXCL4 secretion. Nat Med. (2014) 20:1315-20. doi: 10.1038/n m.3707

154. Zhao M, Perry JM, Marshall H, Venkatraman A, Qian P, He XC, et al. Megakaryocytes maintain homeostatic quiescence and promote post-injury regeneration of hematopoietic stem cells. Nat Med. (2014) 20:13216. doi: $10.1038 / \mathrm{nm} .3706$ 
155. Zoumbos NC, Ferris WO, Hsu SM, Goodman S, Griffith P, Sharrow SO, et al. Analysis of lymphocyte subsets in patients with aplastic anaemia. $\mathrm{Br}$ J Haematol. (1984) 58:95-105. doi: 10.1111/j.1365-2141.1984.tb06063.x

156. Maciejewski JP, Selleri C, Sato T, Anderson S, Young NS. A severe and consistent deficit in marrow and circulating primitive hematopoietic cells (long-term culture-initiating cells) in acquired aplastic anemia. Blood. (1996) 88:1983-91. doi: 10.1182/blood.V88.6.1983.bloodjournal8861983

157. Sloand E, Kim S, Maciejewski JP, Tisdale J, Follmann D, Young NS. Intracellular interferon-gamma in circulating and marrow $\mathrm{T}$ cells detected by flow cytometry and the response to immunosuppressive therapy in patients with aplastic anemia. Blood. (2002) 100:118591. doi: 10.1182/blood-2002-01-0035

158. Morinet F, Leruez-Ville M, Pillet S, Fichelson S. Concise review: Anemia caused by viruses. Stem Cells. (2011) 29:1656-60. doi: 10.1002/stem.725

159. Young NS. Aplastic anemia. N Engl J Med. (2018) 379:164356. doi: 10.1056/NEJMra1413485

160. Chen J, Lipovsky K, Ellison FM, Calado RT, Young NS. Bystander destruction of hematopoietic progenitor and stem cells in a mouse model of infusion-induced bone marrow failure. Blood. (2004) 104:16718. doi: 10.1182/blood-2004-03-1115

161. Maciejewski JP, Rivera C, Kook H, Dunn D, Young NS. Relationship between bone marrow failure syndromes and the presence of glycophosphatidyl inositol-anchored protein-deficient clones. Br J Haematol. (2001) 115:101522. doi: 10.1046/j.1365-2141.2001.03191.x

162. Dufour C, Corcione A, Svahn J, Haupt R, Poggi V, Beka'ssy AN, et al. TNFalpha and IFN-gamma are overexpressed in the bone marrow of Fanconi anemia patients and TNF-alpha suppresses erythropoiesis in vitro. Blood. (2003) 102:2053-9. doi: 10.1182/blood-2003-01-0114

163. Chen J, Feng X, Desierto MJ, Keyvanfar K, Young NS. IFNgamma-mediated hematopoietic cell destruction in murine models of immune-mediated bone marrow failure. Blood. (2015) 126:2621-31. doi: 10.1182/blood-2015-06-652453

164. Sun W, Wu Z, Lin Z, Hollinger M, Chen J, Feng X, et al. Macrophage TNF-alpha licenses donor $\mathrm{T}$ cells in murine bone marrow failure and can be implicated in human aplastic anemia. Blood. (2018) 132:273043. doi: 10.1182/blood-2018-05-844928

165. Park M, Park CJ, Jang S, Kim DY, Lee JH, Lee JH, et al. Reduced expression of osteonectin and increased natural killer cells may contribute to the pathophysiology of aplastic anemia. Appl Immunohistochem Mol Morphol. (2015) 23:139-45. doi: 10.1097/PAI.0000000000000023

166. Vila-del Sol V, Punzon C, Fresno M. IFN-gamma-induced TNF-alpha expression is regulated by interferon regulatory factors 1 and 8 in mouse macrophages. J Immunol. (2008) 181:4461-70. doi: 10.4049/jimmunol.181.7.4461

167. MacNamara KC. The role of interferon, inflammation and infection in aplastic anemia. Blood. (2019) 134(Suppl.):SCI34. doi: 10.1182/blood-2019-121036

168. Genovese G, Kahler AK, Handsaker RE, Lindberg J, Rose SA, Bakhoum SF, et al. Clonal hematopoiesis and blood-cancer risk inferred from blood DNA sequence. N Engl J Med. (2014) 371:2477-87. doi: 10.1056/NEJMoa1409405

169. Tefferi A, Vardiman JW. Myelodysplastic syndromes. N Engl J Med. (2009) 361:1872-85. doi: 10.1056/NEJMra0902908

170. Kook H, Zeng W, Guibin C, Kirby M, Young NS, Maciejewski JP. Increased cytotoxic $\mathrm{T}$ cells with effector phenotype in aplastic anemia and myelodysplasia. Exp Hematol. (2001) 29:1270-7. doi: 10.1016/S0301-472X(01)00736-6

171. Raza A, Mundle S, Shetty V, Alvi S, Chopra H, Span L, et al. Novel insights into the biology of myelodysplastic syndromes: excessive apoptosis and the role of cytokines. Int J Hematol. (1996) 63:265-78.

172. Basiorka AA, McGraw KL, Eksioglu EA, Chen X, Johnson J, Zhang L, et al. The NLRP3 inflammasome functions as a driver of the myelodysplastic syndrome phenotype. Blood. (2016) 128:2960-75. doi: 10.1182/blood-2016-07-730556

173. Balderman SR, Calvi LM. Biology of BM failure syndromes: role of microenvironment and niches. Hematology Am Soc Hematol Educ Program. (2014) 2014:71-6. doi: 10.1182/asheducation-2014.1.71

174. Pronk E, Raaijmakers M. The mesenchymal niche in MDS. Blood. (2019) 133:1031-8. doi: 10.1182/blood-2018-10-844639
175. Ping Z, Chen S, Hermans SJF, Kenswil KJG, Feyen J, van Dijk C, et al. Activation of NF-kappaB driven inflammatory programs in mesenchymal elements attenuates hematopoiesis in low-risk myelodysplastic syndromes. Leukemia. (2019) 33:536-541. doi: 10.1038/s41375-018-0267-x

176. Han Y, Wang H, Shao Z. Monocyte-derived macrophages are impaired in myelodysplastic syndrome. J Immunol Res. (2016) 2016:5479013. doi: 10.1155/2016/5479013

177. Nagata Y, Makishima H, Kerr CM, Przychodzen BP, Aly M, Goyal $A$, et al. Invariant patterns of clonal succession determine specific clinical features of myelodysplastic syndromes. Nat Commun. (2019) 10:5386. doi: 10.1038/s41467-019-13001-y

178. Cull AH, Snetsinger B, Buckstein R, Wells RA, Rauh MJ. Tet2 restrains inflammatory gene expression in macrophages. Exp Hematol. (2017) 55:5670.e13. doi: 10.1016/j.exphem.2017.08.001

179. Cull AH, Mahendru D, Snetsinger B, Good D, Tyryshkin K, Chesney A, et al. Overexpression of Arginase 1 is linked to DNMT3A and TET2 mutations in lower-grade myelodysplastic syndromes and chronic myelomonocytic leukemia. Leuk Res. (2018) 65:5-13. doi: 10.1016/j.leukres.2017.12.003

180. Mejia-Ramirez E, Florian MC. Understanding intrinsic hematopoietic stem cell aging. Haematologica. (2020) 105:2237. doi: 10.3324/haematol.2018.211342

181. Ho YH, Mendez-Ferrer S. Microenvironmental contributions to hematopoietic stem cell aging. Haematologica. (2020) 105:38-46. doi: 10.3324/haematol.2018.211334

182. Young K, Borikar S, Bell R, Kuffler L, Philip V, Trowbridge JJ. Progressive alterations in multipotent hematopoietic progenitors underlie lymphoid cell loss in aging. J Exp Med. (2016) 213:2259-67. doi: 10.1084/jem.20160168

183. Liang Y, van Zant G, Szilvassy SJ. Effects of aging on the homing and engraftment of murine hematopoietic stem and progenitor cells. Blood. (2005) 106:1479-87. doi: 10.1182/blood-2004-11-4282

184. Ho YH, Del Toro R, Rivera-Torres J, Rak J, Korn C, Garcia-Garcia A, et al. Remodeling of bone marrow hematopoietic stem cell niches promotes myeloid cell expansion during premature or physiological aging. Cell Stem Cell. (2019) 25:407-18.e6. doi: 10.1016/j.stem.2019.06.007

185. Frisch BJ, Hoffman CM, Latchney SE, LaMere MW, Myers J, Ashton J, et al. Aged marrow macrophages expand platelet-biased hematopoietic stem cells via Interleukin1B. JCI Insight. (2019) 5:e124213. doi: 10.1172/jci.insight.124213

186. Kohler A, Schmithorst V, Filippi MD, Ryan MA, Daria D, Gunzer M, et al. Altered cellular dynamics and endosteal location of aged early hematopoietic progenitor cells revealed by time-lapse intravital imaging in long bones. Blood. (2009) 114:290-8. doi: 10.1182/blood-2008-12-195644

187. Scheinberg P, Young NS. How I treat acquired aplastic anemia. Blood. (2012) 120:1185-96. doi: 10.1182/blood-2011-12-274019

188. Oishi Y, Manabe I. Macrophages in age-related chronic inflammatory diseases. NPJ Aging Mech Dis. (2016) 2:16018. doi: 10.1038/npjamd.2016.18

189. A-Gonzalez N, Quintana JA, Garcia-Silva S, Mazariegos M, de la Aleja AG, Nicolas-Avila JA, et al. Phagocytosis imprints heterogeneity in tissue-resident macrophages. J Exp Med. (2017) 214:1281-96. doi: 10.1084/jem.20161375

190. Jaiswal S, Natarajan P, Silver AJ, Gibson CJ, Bick AG, Shvartz E, et al. Clonal hematopoiesis and risk of atherosclerotic cardiovascular disease. $N$ Engl J Med. (2017) 377:111-21. doi: 10.1056/NEJMoa1701719

191. Fuster JJ, MacLauchlan S, Zuriaga MA, Polackal MN, Ostriker AC, Chakraborty R, et al. Clonal hematopoiesis associated with TET2 deficiency accelerates atherosclerosis development in mice. Science. (2017) 355:8427. doi: $10.1126 /$ science.aag1381

Conflict of Interest: The authors declare that the research was conducted in the absence of any commercial or financial relationships that could be construed as a potential conflict of interest.

Copyright (C) 2020 Seyfried, Maloney and MacNamara. This is an open-access article distributed under the terms of the Creative Commons Attribution License (CC BY). The use, distribution or reproduction in other forums is permitted, provided the original author(s) and the copyright owner(s) are credited and that the original publication in this journal is cited, in accordance with accepted academic practice. No use, distribution or reproduction is permitted which does not comply with these terms. 